\title{
Long-Range PCR-Based NGS Applications to Diagnose Mendelian Retinal Diseases
}

\section{Journal Article}

\section{Author(s):}

Maggi, Jordi; Koller, Samuel; Bähr, Luzy; Feil, Silke; Kivrak Pfiffner, Fatma; Hanson, James V.M.; Maspoli, Alessandro; GerthKahlert, Christina; Berger, Wolfgang

\section{Publication date:}

2021-02

\section{Permanent link:}

https://doi.org/10.3929/ethz-b-000468396

\section{Rights / license:}

Creative Commons Attribution 4.0 International

\section{Originally published in:}

International Journal of Molecular Sciences 22(4), https://doi.org/10.3390/ijms22041508 


\title{
Article \\ Long-Range PCR-Based NGS Applications to Diagnose Mendelian Retinal Diseases
}

\author{
Jordi Maggi ${ }^{1}{ }^{\circledR}$, Samuel Koller ${ }^{1}\left(\mathbb{D}\right.$, Luzy Bähr ${ }^{1}$, Silke Feil ${ }^{1}$, Fatma Kivrak Pfiffner ${ }^{1}$, James V. M. Hanson ${ }^{2}$, \\ Alessandro Maspoli ${ }^{1}$, Christina Gerth-Kahlert ${ }^{2} \mathbb{C}$ and Wolfgang Berger $1,3,4, *$ (])
}

1 Institute of Medical Molecular Genetics, University of Zurich, 8952 Schlieren, Switzerland; maggi@medmolgen.uzh.ch (J.M.); koller@medmolgen.uzh.ch (S.K.); baehr@medmolgen.uzh.ch (L.B.); feil@medmolgen.uzh.ch (S.F.); kivrakpfiffner@medmolgen.uzh.ch (F.K.P.); maspoli@medmolgen.uzh.ch (A.M.)

2 Department of Ophthalmology, University Hospital Zurich and University of Zurich, 8091 Zurich, Switzerland; james.hanson@usz.ch (J.V.M.H.); christina.gerth-kahlert@usz.ch (C.G.-K.)

3 Zurich Center for Integrative Human Physiology (ZIHP), University of Zurich, 8057 Zurich, Switzerland

4 Neuroscience Center Zurich (ZNZ), University and ETH Zurich, 8057 Zurich, Switzerland

* Correspondence: berger@medmolgen.uzh.ch; Tel.: +41-44-556-33-50

check for updates

Citation: Maggi, J.; Koller, S.; Bähr, L.; Feil, S.; Kivrak Pfiffner, F.; Hanson, J.V.M.; Maspoli, A.; Gerth-Kahlert, C.; Berger, W. Long-Range PCR-Based NGS Applications to Diagnose Mendelian Retinal Diseases. Int. J. Mol. Sci. 2021, 22, 1508. https:// doi.org/10.3390/ijms22041508

Academic Editor: Tomasz Żarnowski

Received: 4 January 2021

Accepted: 28 January 2021

Published: 3 February 2021

Publisher's Note: MDPI stays neutral with regard to jurisdictional claims in published maps and institutional affiliations.

Copyright: (c) 2021 by the authors. Licensee MDPI, Basel, Switzerland. This article is an open access article distributed under the terms and conditions of the Creative Commons Attribution (CC BY) license (https:// creativecommons.org/licenses/by/ $4.0 /)$.

\begin{abstract}
The purpose of this study was to develop a flexible, cost-efficient, next-generation sequencing (NGS) protocol for genetic testing. Long-range polymerase chain reaction (PCR) amplicons of up to $20 \mathrm{~kb}$ in size were designed to amplify entire genomic regions for a panel $(n=35)$ of inherited retinal disease (IRD)-associated loci. Amplicons were pooled and sequenced by NGS. The analysis was applied to 227 probands diagnosed with IRD: (A) 108 previously molecularly diagnosed, (B) 94 without previous genetic testing, and (C) 25 undiagnosed after whole-exome sequencing (WES). The method was validated with $100 \%$ sensitivity on cohort A. Long-range PCR-based sequencing revealed likely causative variant(s) in $51 \%$ and $24 \%$ of proband from cohorts B and C, respectively. Breakpoints of 3 copy number variants (CNVs) could be characterized. Long-range PCR libraries spike-in extended coverage of WES. Read phasing confirmed compound heterozygosity in 5 probands. The proposed sequencing protocol provided deep coverage of the entire gene, including intronic and promoter regions. Our method can be used (i) as a first-tier assay to reduce genetic testing costs, (ii) to elucidate missing heritability cases, (iii) to characterize breakpoints of CNVs at nucleotide resolution, (iv) to extend WES data to non-coding regions by spiking-in long-range PCR libraries, and (v) to help with phasing of candidate variants.
\end{abstract}

Keywords: genetic testing; retinal diseases; sequencing; NGS; diagnostics; long-range PCR; CNV; phasing; missing heritability; $A B C A 4$; PRPH2; BEST1

\section{Introduction}

Inherited retinal diseases (IRDs) are a group of disorders affecting the retina and its function. They are characterized by high phenotypic variability and genetic heterogeneity, including different modes of inheritance [1]. These disorders may present as either isolated or syndromic, progressive or stationary. Also, IRDs may affect the entire retina (panretinal) or may be restricted to the macula. Moreover, they are often classified based on the primarily affected photoreceptor type. Panretinal forms include retinitis pigmentosa $(\mathrm{RP})$, cone-rod dystrophy (CRD), cone dystrophy (COD), and others, whereas macular dystrophies (MDs) include Stargardt disease (STGD), Best disease (BEST), and others [1,2].

Due to the multitude of loci associated with IRDs (almost 300 loci, https://sph. uth.edu/RetNet), molecular diagnostics often relies on targeted enrichment and highthroughput sequencing, either whole-exome (WES) [3-6] or gene panels [5-10]. Studies have reported that diagnostic yield when using these standard methods (WES/gene panels) is typically between $50 \%$ and $76 \%$, depending, amongst other factors, on the specific clinical subtype being investigated $[6-9,11-14]$. 
Missing heritability is defined as the portion of the phenotypic trait that could not (yet) be explained by genotype data [15]. Since inherited diseases are, by definition, characterized by complete or near-complete heritability, missing heritability in these diseases indicates cases in which genetic testing could not identify a molecular diagnosis [15].

Recent efforts to reduce missing heritability in IRDs (and improve diagnostic output) have focused on non-coding regions of the genome, and on the detection of structural or copy number variants (CNVs) [16-19]. These studies were performed using customized microarray probes [17], customized capturing probes [16,18], or genome sequencing [19].

Several studies have focused on the $A B C A 4$ locus $[16,18,20-23]$, as it has often been reported to be one of the most prevalent mutated genes in IRD cohorts [10,12-14,24]. Variants in this gene are the cause of STGD1 (MIM 248200) [25]. Previous studies have reported that $15-40 \%$ of STGD patients remain without a molecular diagnosis after standard genetic testing $[16,18,20-23,26]$. These studies identified CNVs and several non-canonical splice site and deep-intronic variants that have been shown to affect splicing, findings that partially explain missing heritability in STGD $[16,18,20-23]$.

Here, we present a flexible and cost-effective method to comprehensively sequence loci of interest. The method relies on high-throughput sequencing of pooled long-range (LR) polymerase chain reaction (PCR) fragments of up to $20 \mathrm{~kb}$ in size. We designed primers to sequence 35 genomic loci that have been associated with IRDs, particularly MDs and X-linked RP, including ABCA4, PRPH2, BEST1, CRB1, CNGB3, RP1, and RPGR.

\section{Results}

LR PCRs were established for 35 loci associated with IRDs. The total genomic target equals $1.81 \mathrm{Mb}$, and the longest locus is CRB1, with a total genomic target of $212 \mathrm{~kb}$ (Table 1). The entire regions of most target genes could be amplified and sequenced. Several intronic regions could not be amplified after several attempts: CRB1 (3.8 kb in size, NC_000001.10:g.197420721-197424549), EFEMP1 (0.5 kb, NC_000002.11:5610226156102747), IMPG1 (1.9 kb, NC_000006.11:76729633-76731567 and $1.6 \mathrm{~kb}$, NC_000006.11: 76633571-76635199), CNGB3 (7.1 kb, NC_000008.10:g.87647022-87654129 and $3.8 \mathrm{~kb}, \mathrm{NC}_{-}$ 000008.10:87625835-87629598), and TIMP3 (1.5 kb, NC_000022.10:33202359-33203885).

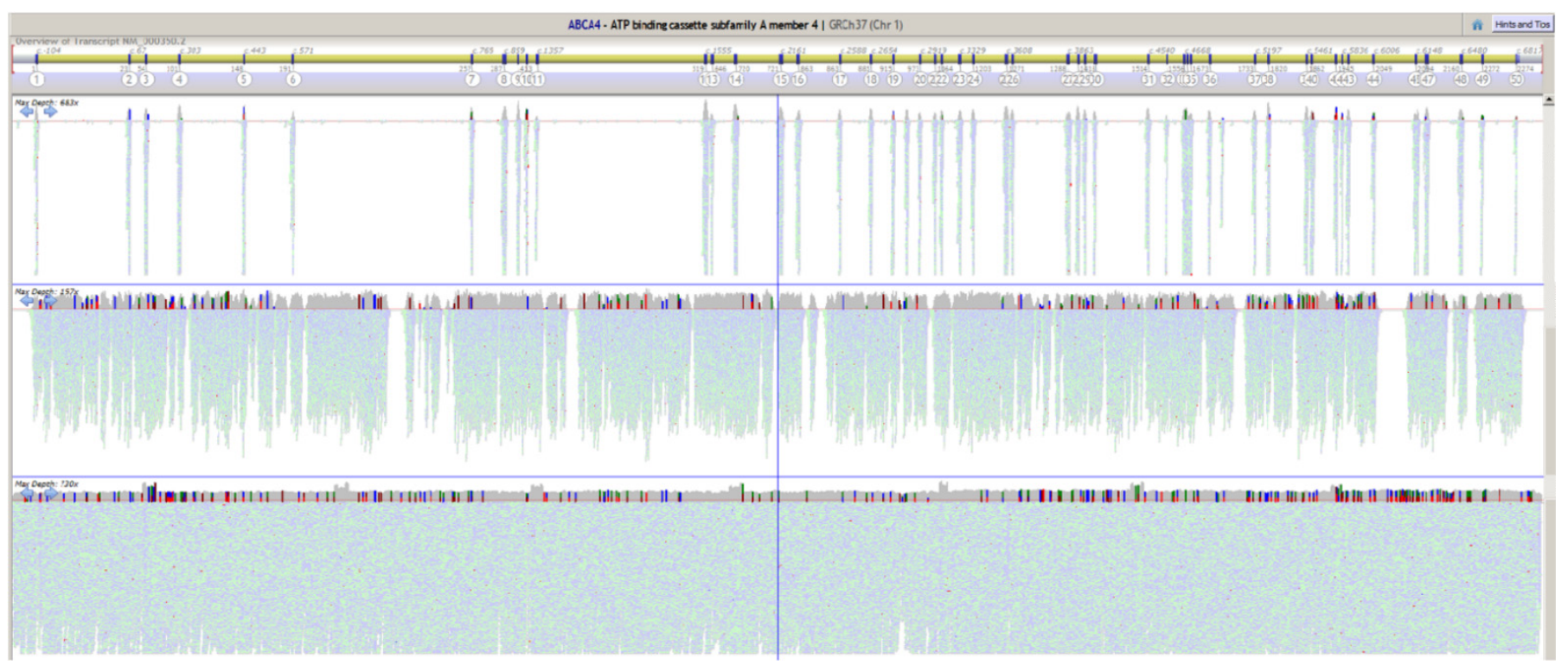

Figure 1. $A B C A 4$ coverage comparison of different assays. Screenshot of the Alamut Visual software showing the coverage results for the $A B C A 4$ locus from different next-generation sequencing assays. On the top, the software illustrates the relative exon locations. Below the gene structure, coverage plots for a typical whole-exome sequencing assay (top), custom capture probes assay (middle), and, finally, the long-range polymerase chain reaction method (bottom). 
Table 1. Established long-range polymerase chain reactions (PCRs) for retinal diseases-associated loci. The first column indicates the names of the loci included in the panel, ordered by chromosome coordinates. The second column highlights the number of PCRs necessary to cover the locus comprehensively, and the last column shows the total size of the genomic target sequence. Abbreviations: bp, base pairs.

\begin{tabular}{|c|c|c|}
\hline Locus & Number of PCRs Needed & Genomic Target Size (bp) \\
\hline PPT1 & 2 & 26,746 \\
\hline$A B C A 4$ & 8 & 137,748 \\
\hline CRB1 & 14 & 212,898 \\
\hline PCARE & 1 & 18,628 \\
\hline EFEMP1 & 5 & 60,569 \\
\hline IMPG2 & 6 & 94,768 \\
\hline PROM1 & 7 & 117,712 \\
\hline MFSD8 & 3 & 49,747 \\
\hline CTNNA1 & 13 & 182,694 \\
\hline GUCA1A & 2 & 27,191 \\
\hline GUCA1B & 1 & 13,548 \\
\hline PRPH2 & 2 & 32,242 \\
\hline IMPG1 & 11 & 144,700 \\
\hline ELOVL4 & 2 & 34,792 \\
\hline DHS6S1 & 1 & 13,473 \\
\hline RP1L1 & 3 & 51,877 \\
\hline$R P 1$ & 1 & 16,930 \\
\hline CNGB3 & 12 & 172,052 \\
\hline KCNV2 & 1 & 15,214 \\
\hline ATOH7 & 1 & 9275 \\
\hline PDE6C & 3 & 53,794 \\
\hline BEST1 & 1 & 17,272 \\
\hline C1QTNF5 & 1 & 10,536 \\
\hline PDE6H & 1 & 11,084 \\
\hline RDH5 & 1 & 6122 \\
\hline OTX2 & 1 & 12,758 \\
\hline NR2E3 & 1 & 11,097 \\
\hline$R L B P 1$ & 1 & 13,667 \\
\hline GUCY2D & 1 & 18,939 \\
\hline FSCN2 & 1 & 11,574 \\
\hline$R A X 2$ & 1 & 5845 \\
\hline TIMP3 & 5 & 67,146 \\
\hline$R S 1$ & 3 & 34,731 \\
\hline$R P G R$ & 4 & 60,808 \\
\hline$R P 2$ & 3 & 46,521 \\
\hline
\end{tabular}

The primers for loci that require multiple PCRs were designed in a way that amplicons of adjacent regions overlap with each other. As an example, Figure 1 shows the coverage obtained for the $A B C A 4$ locus by different NGS assays: WES, custom capture probes, and LR PCRs.

As per design, WES only provides coverage for the coding portions of the locus. The custom capture probes result in coverage for the majority of the locus, including introns. However, gaps accounting for $15-20 \%$ of the locus are present. Finally, the LR PCR method can provide uniform coverage over the entire locus. Overlaps between neighboring LR amplicons are revealed by an increase in coverage. Similar results were obtained for the other loci included in the panel (Figure S1 in the Supplementary Materials).

In order to verify sensitivity of the method, 108 IRD patients were selected, for whom a molecular diagnosis had been previously established, corresponding to variants in a locus included in the panel. LR PCRs for the respective loci were performed and sequenced. The sequencing of the validation cohort resulted in $100 \%$ sensitivity to the previously identified putative pathogenic variants (Table A1 in the Appendix A). We found no evidence for allele dropout (ADO). 
We envisioned the method to be useful in the following scenarios.

\subsection{First-Tier Assay for Probands without Previous Genetic Testing}

A subpanel of the 35 loci was selected and sequenced for 94 non-syndromic IRD cases composed of probands diagnosed with MD (92/94), CRD (1/94), and autosomal dominant COD (1/94) that had not previously undergone genetic testing. Locus selection was based on the provided clinical diagnosis and family history. This strategy resulted in the identification of a molecular diagnosis in $48 / 94$ probands (51.1\%) (Table A2 in the Appendix A).

If candidate loci sequencing did not reveal a molecular diagnosis, WES was performed. Second-tier WES analysis revealed likely pathogenic variants in 15 additional probands, resulting in a total of 63/94 molecularly diagnosed probands (Table A2 in the Appendix A). Thirty-one probands (33.0\%) were still lacking a genetic diagnosis after first-tier LR PCR-based candidate loci sequencing and second-tier WES. A list of rare variants (gnomAD MAF $<1 \%$ ) found in these samples is provided (Table S1 in the Supplementary Materials).

\subsection{Tackling Missing Heritability}

The missing heritability cohort included 25 probands, in whom WES was previously performed and a single likely pathogenic variant in a recessively inherited locus was identified. LR PCRs of the relevant loci (i.e., those carrying a single likely pathogenic variant) were performed to assess the presence of a second likely pathogenic variant.

This strategy led to the discovery of additional likely pathogenic variants in $A B C A 4$ in $6 / 25$ probands $(23.1 \%)$. The most common likely causative variant identified is NM_000350. 2:c.5603A > T ( 3 alleles), which is often excluded from analysis due to the relatively high minor allele frequency in gnomAD (6.65\% in Non-Finnish European) [18]. The remaining cases could be explained by the discovery of previously published deep intronic variants: NM_000350.2:c.4253 + 43G > A [21,22], NM_000350.2:c.4539 + 2064C > T [18,20], and NM_000350.2:c.5196 + 1056A > G [16,20] (Table A3 in the Appendix A). Moreover, this strategy led to the detection of several deep-intronic variants of unknown significance, which require further analyses for interpretation of pathogenicity (Table S1 in the Supplementary Materials).

\subsection{Copy Number Variant (CNV) Characterization}

$\mathrm{CNV}$ analysis on capture data allowed for the identification of likely pathogenic exon-spanning deletions in $A B C A 4, K C N V 2, R P 1$, and $R S 1$.

A heterozygous $A B C A 4$ deletion spanning exons 20 through 22 and parts of the adjacent introns was identified in two unrelated STGD patients and confirmed by multiplex ligation-dependent probe amplification (MLPA; Figure A1 and Table A2). A LR PCR product generated by using forward and reverse primers upstream of exon 19 and downstream of exon 23, respectively, was sequenced on a MiSeq instrument (Illumina, San Diego, CA, USA). Results highlighted similar breakpoints as in a recently published recurrent deletion [18]; however, mismatches and a longer polyadenine stretch seem to be present around the breakpoints. The breakpoint region was also sequenced by targeted locus amplification (TLA; Cergentis, Utrecht, The Netherlands), which appeared to confirm the 3' breakpoint at NC_000001.10:g.94511701. The 5' breakpoint probably lies within an A-rich sequence at NC_000001.10:g.94507655-94507699. Interestingly, the breakpoints are flanked by an AluY and an AluSx element on the 5' - (NC_000001.10:g.94507370-94507684) and 3'-side (NC_000001.10:g.94511717-94512041), respectively. Finally, a 10 bp microhomology sequence directly follows the $5^{\prime}$-side AluY element (NC_000001.10:g.94507690-94507699) and precedes the $3^{\prime}$-side AluSx element (NC_000001.10:g.94511701-94511710). However, unambiguous breakpoint identification was not possible due to repetitive flanking sequences (Table A2 and Figure A1).

A heterozygous deletion spanning the entire $K C N V 2$ locus was identified in a patient diagnosed with COD (Table A1 in the Appendix A). To narrow down the breakpoint region 
of the deletion, microarray analysis was performed with an $850 \mathrm{~K}$ single nucleotide polymorphism (SNP) chip. Based on these results, primers were designed for LR and the resulting amplicon was sequenced. Sequence alignment revealed a deletion of 70,036 bp in size and a 3 bp microhomology sequence flanking the breakpoints (Table A1 and Figure A2).

Finally, a hemizygous deletion involving exon 2 of RS1 and a homozygous deletion spanning exons 2-4 of RP1 were identified in a X-linked retinoschisis (XLRS) patient and a $\mathrm{RP}$ patient, respectively. The breakpoints of these deletions could be determined directly with the validated LR PCRs (Table S2 in the Supplementary Materials). The RP1 deletion is $11,116 \mathrm{bp}$ in length with a $3 \mathrm{bp}$ microhomology region flanking the breakpoints and has been described previously [27] (Table A1 in the Appendix A). The RS1 deletion is $1005 \mathrm{bp}$ in length and features a $4 \mathrm{bp}$ microhomology around the breakpoints (Table A1 and Figure A3).

\subsection{Exome Spike-In}

In order to include the intronic regions of $A B C A 4$, custom-capture probes were added to the TruSeq Exome kit capture probes before the hybridization step. The resulting data provided low coverage of the intronic regions of the gene (Figure S2 in the Supplementary Materials). However, achieving the appropriate dilutions and proportions to ensure that the $A B C A 4$ capture probes do not outnumber WES probes was challenging.

Similarly, LR PCR libraries spike-in was performed for the ABCA4, RPGR, and PCARE (C2orf71), to either increase coverage of poorly captured regions, such as RPGR's exon ORF15 (open reading frame 15) and PCARE exon 1, or to cover non-captured regions, such as introns. The method provided reliable data for variant detection over the entire loci, including exon ORF15 (Figure S2 in the Supplementary Materials). Moreover, it proved to be technically less challenging compared to custom probes spike-in. Finally, the extra target regions can be personalized for each individual sample.

\subsection{Read Phasing}

In case of compound heterozygosity for recessive variants, chromosomal phasing for the candidate variants should be performed. Segregation analysis can achieve this, but only if family members are available for testing. Additional family members of 66 probands were available for segregation analysis in this study $(66 / 227,29.1 \%)$.

Being able to perform chromosome phasing directly on an individual's sample would greatly help with interpretation of genetic testing results. By visually inspecting reads resulting from LR PCR sequencing (read phasing), it was possible to ascertain compound heterozygosity in 5 cases (Tables A1-A3 in the Appendix A). Figure 2 shows a graphic representation of the concept (a), along with the simplest specific example (patient ID S220, Table A2) (b).

\subsection{Macular Dystrophies (MD) Cohort}

MD cases were present in all three groups analyzed in this study: 70 in the validation cohort, 13 in the missing heritability group, and 85 in the cohort in whom genetic testing had not been previously performed. The MD cohort $(\mathrm{N}=168)$ was composed of probands with clinical diagnosis of STGD $(n=95)$, unspecified MD $(n=45)$, Best disease $(n=11)$, malattia leventinese (ML; $n=9$ ), XLRS $(n=6)$, Sorsby fundus dystrophy (SFD; $n=1$ ), and adult vitelliform macular dystrophy (AVMD; $n=1)$ (Table 2). The overall diagnostic yield equals $78.6 \%$, with the STGD sub-cohort reaching $88.4 \%$ detection rate (Table 2 and Figure 3). Moreover, similar to previously reported findings [13,14], ABCA4 $(n=75)$, PRPH2 $(n=17)$, and BEST1 $(n=10)$ are the most common contributors in our cohort (Figure 3). 


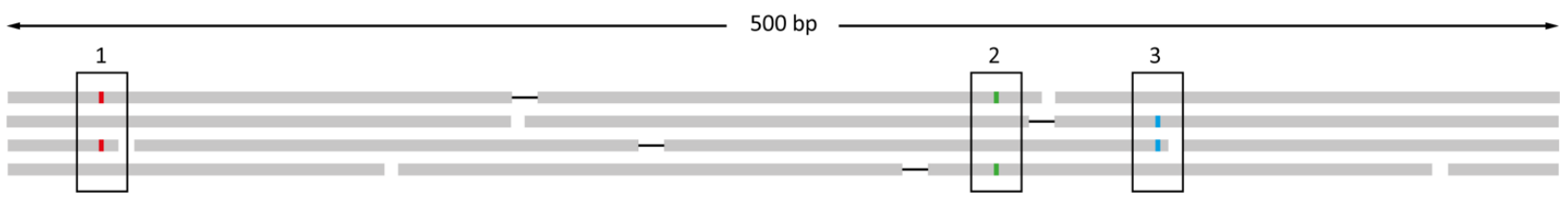

(a) Read phasing concept

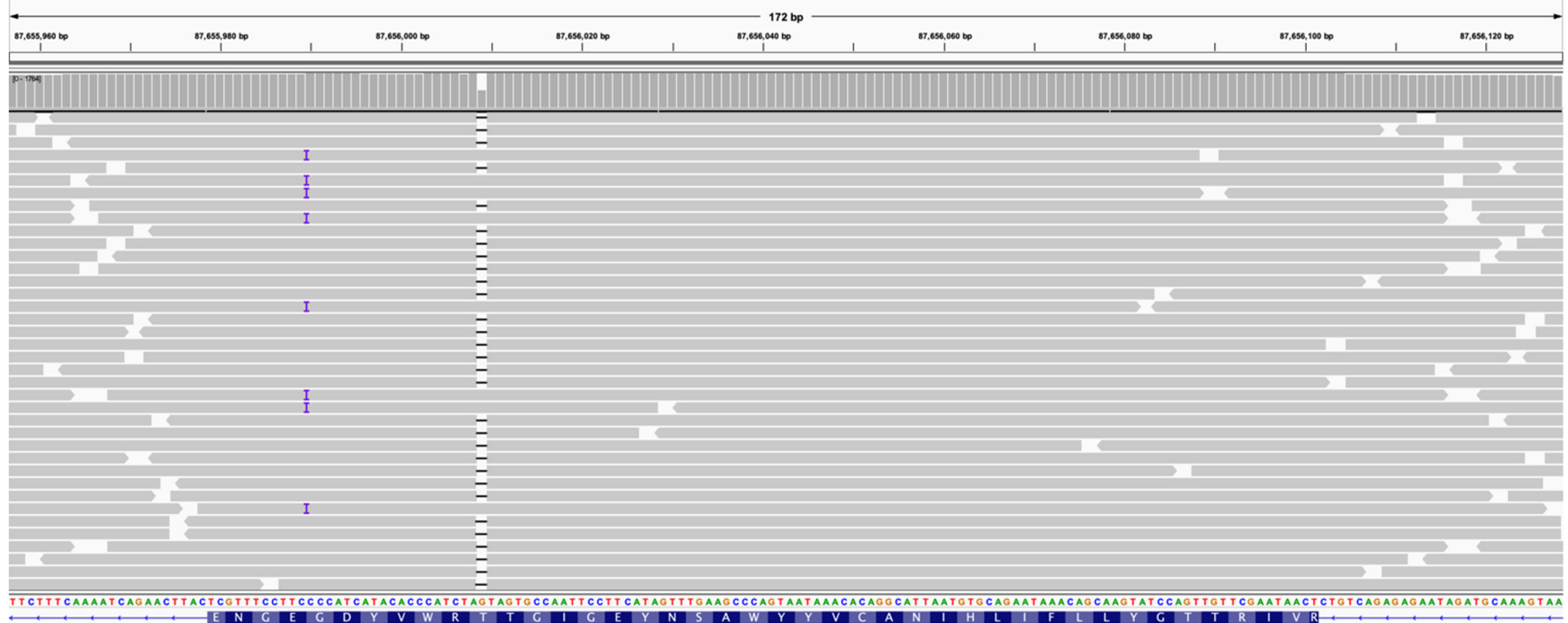

(b) Read phasing example

Figure 2. Read phasing: (a) Conceptual representation of read phasing. The grey bars represent sequencing reads aligned to the genome. Mate pair reads are connected by a black line. Single nucleotide variants are shown by a colored line and highlighted by black boxes. In this representation, variants at position 1 and 3 are the two putative pathogenic variants. The mate pair read on the top left is evidence that variants 1 and 2 are in cis. On the other hand, mate pair reads on the second and third lines attest that variants 2 and 3 are in trans. Therefore, variants 1 and 3 are in trans. (b) Screenshot from Integrative Genomics Viewer (IGV) of a simple example of read phasing from this study. The illustration shows the location of the two potentially pathogenic variants for patient S220 (CNGB3:c.1148del and CNGB3:c.1167_1168insC).

Table 2. Macular dystrophies (MD) cohort summary. Abbreviations: STGD, Stargardt disease; MD, macular dystrophy; BEST, Best disease; ML, malattia leventinese; XLRS, X-linked retinoschisis; SFD, Sorsby fundus dystrophy.

\begin{tabular}{cccccc}
\hline Category & Total & $\begin{array}{c}\text { Total } \\
\text { Diagnosed }\end{array}$ & $\begin{array}{c}\text { Total } \\
\text { Undiagnosed }\end{array}$ & $\begin{array}{c}\text { Mean Age at } \\
\text { Referral } \\
\text { (Years) }\end{array}$ & $\begin{array}{c}\text { Diagnostic } \\
\text { Yield (\%) }\end{array}$ \\
\hline Overall & 168 & 132 & 36 & 37.86 & 78.6 \\
\hline Stratification group & & & & & \\
Validation & 70 & 70 & 0 & 35.60 & 100.0 \\
No previous testing & 85 & 58 & 27 & 40.14 & 68.2 \\
Missing heritability & 13 & 4 & 9 & 35.08 & 30.8 \\
\hline Clinical diagnosis & & & & & \\
STGD & 95 & 84 & 11 & 35.88 & 88.4 \\
Unspecified MD & 45 & 28 & 17 & 40.11 & 62.2 \\
BEST & 11 & 9 & 2 & 35.73 & 81.8 \\
ML & 9 & 5 & 4 & 47.89 & 55.6 \\
XLRS & 6 & 6 & 0 & 32.00 & 100.0 \\
SFD & 1 & 0 & 1 & 63.00 & 0.0 \\
\hline
\end{tabular}




\section{Macular dystrophies}
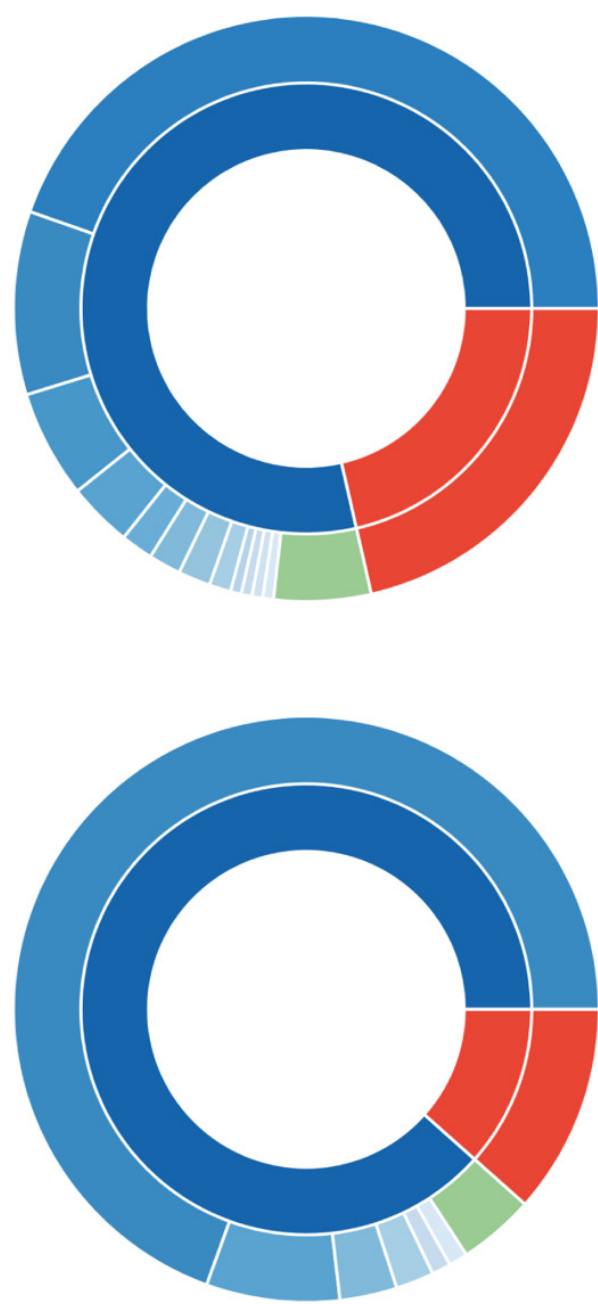

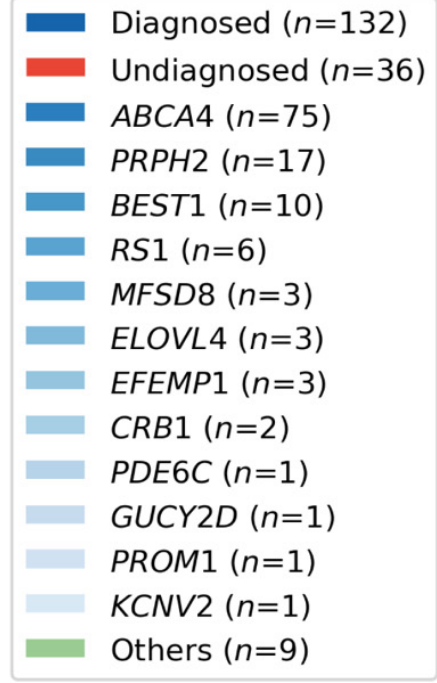

\section{Stargardt disease}

Figure 3. Diagnostic yields and main contributing loci for the macular dystrophies cohort and for the Stargardt disease sub-cohort. Nested pie charts depicting diagnostic yield (inner ring) and the identified contributing loci (outer ring) for macular dystrophies (top) and Stargardt disease (bottom). The loci included in the long-range polymerase chain reaction (PCR) panel are shown in different shades of blue, whilst other retinal diseases-associated loci not included in the panel are shown in green. $A B C A 4$ and $P R P H 2$ are the main contributors in both cohorts.

A total of 161 unique, likely pathogenic variants were deemed disease-relevant in our cohort, with 39 being novel (not found in Human Gene Mutation Database; summarized in Table 3). Of these 161 variants, 127 were single nucleotide variants (26 novel), 30 small indels (10 novel), and 4 larger deletions (3 novel). The most common causal variants were NM_000350.2(ABCA4):c.5882G > A (35 alleles), NM_000322.4(PRPH2):c.514C > T (11 alleles), NM_000350.2(ABCA4):c.5603A > T (not in cis with other known causal variants, 10 alleles), NM_000350.2(ABCA4):c.5714 + 5G > A (9 alleles), NM_000350.2(ABCA4):c.[5461$10 \mathrm{~T}>\mathrm{C} ; 5603 \mathrm{~A}>\mathrm{T}]$ (7 alleles), NM_000350.2(ABCA4):c.[1622T > C;3113C > T] (6 alleles), and NM_000350.2(ABCA4):c.[2588G > C;5603A > T] (6 alleles). Among the novel findings (Table 3), there are three recurrent likely pathogenic variants: NM_000350.2(ABCA4):c.4958G > A (2 alleles), NM_152778.2(MFSD8):c.670A > T (3 alleles), and NM_133497.3(KCNV2):c. 1096del (2 alleles, found once in an undiagnosed case). 
Table 3. Novel likely pathogenic variants. Abbreviations: cNomen, Human Genome Variation Society (HGVS) cDNA-level nucleotide change nomenclature; pNomen, predicted protein-level change nomenclature; gnomAD, genome aggregation database minor allele frequency; ACMG, American College of Medical Genetics and Genomics guidelines; CADD, Combined Annotation-Dependent Depletion.

\begin{tabular}{|c|c|c|c|c|c|c|}
\hline Locus & cNomen & pNomen & $\begin{array}{l}\text { GnomAD } \\
\text { Overall (\%) }\end{array}$ & $\begin{array}{l}\text { GnomAD } \\
\text { Max. (\%) }\end{array}$ & $\begin{array}{l}\text { ACMG } \\
\text { Class }\end{array}$ & $\begin{array}{l}\text { CADD } \\
\text { Score }\end{array}$ \\
\hline$A B C A 4$ & NM_000350.2:c.6731T > A & p.Val2244Glu & 0 & 0 & 3 & 27.3 \\
\hline$A B C A 4$ & NM_000350.2:c.6428T > A & p.Met2143Lys & 0 & 0 & 4 & 32.0 \\
\hline$A B C A 4$ & NM_000350.2:c.6323_6331delinsGGC & p.Met2108_Asn2111delinsArgHis & 0 & 0 & 4 & 35 \\
\hline$A B C A 4$ & NM_000350.2:c.5924G > T & p.Gly1975Val & 0 & 0 & 4 & 28.8 \\
\hline$A B C A 4$ & NM_000350.2:c.5690_5704del & p.Gln1897_Phe1901del & 0 & 0 & 3 & 22.2 \\
\hline$A B C A 4$ & NM_000350.2:c.5691G $>$ T & p.Gln 1897 His & 0 & 0 & 3 & 23.8 \\
\hline$A B C A 4$ & NM_000350.2:c.5461-6T > C & p.? & 0 & 0 & 3 & 14.93 \\
\hline$A B C A 4^{1}$ & NM_000350.2:c.4958G > A & p.Gly1653Glu & 0 & 0 & 3 & 28.1 \\
\hline$A B C A 4$ & NM_000350.2:c.4609del & p.Thr1537ArgfsTer6 & 0 & 0 & 4 & 33 \\
\hline$A B C A 4$ & NM_000350.2:c.4383G > C & p.Trp1461Cys & 0.0004 & 0.003 & 3 & 32 \\
\hline$A B C A 4$ & NM_000350.2:c.3323del & p.Arg1108ProfsTer40 & 0 & 0 & 5 & 34 \\
\hline$A B C A 4$ & NM_000350.2:c.3179A > C & p.Gln1060Pro & 0.0008 & 0.0065 & 4 & 23.7 \\
\hline$A B C A 4^{2}$ & $\begin{array}{l}\text { NM_000350.2:c.(2918 + 765_2918 + } \\
\text { 775)_(3328 + 618_3328 + 662)del }\end{array}$ & $\begin{array}{l}\text { p.Leu973_Asp2273delinsPheMetAlaArg } \\
\text { ValGluArgSerLeuGlyAsn }\end{array}$ & 0 & 0 & 5 & \\
\hline$A B C A 4$ & NM_000350.2:c.1742C > A & p.Thr581Asn & 0 & 0 & 3 & 26.7 \\
\hline$A B C A 4$ & NM_000350.2:c.1621_1622del & p.Leu541ThrfsTer14 & 0 & 0 & 4 & 32 \\
\hline$A B C A 4$ & NM_000350.2:c.727_728dup & p.Tyr245CysfsTer18 & 0 & 0 & 5 & 26.2 \\
\hline$A B C A 4$ & NM_000350.2:c.676C > A & p.Arg226Ser & 0.0068 & 0.0163 & 3 & 14.13 \\
\hline CRB1 & NM_201253.2:c.1472A > T & p.Asp491Val & 0 & 0 & 3 & 15.86 \\
\hline CRB1 & NM_201253.2:c.2298G > A & p.Trp766Ter & 0 & 0 & 5 & 36 \\
\hline OPA1 & NM_130837.2:c.2987A > C & p.Lys996Thr & 0 & 0 & 4 & 23.8 \\
\hline PROM1 & NM_006017.2:c.2476G > C & p.Asp826His & 0 & 0 & 3 & 32 \\
\hline MFSD8 ${ }^{1}$ & NM_152778.2:c.670A > T & p.Asn224Tyr & 0 & 0 & 3 & 23.9 \\
\hline GUCA1A & NM_000409.4:c.333G > C & p.Glu111Asp & 0 & 0 & 4 & 22.9 \\
\hline PRPH2 & NM_000322.4:c.611_626del & p.Tyr204SerfsTer47 & 0 & 0 & 5 & 33 \\
\hline PRPH2 & NM_000322.4:c.605G > A & p.Gly202Glu & 0 & 0 & 4 & 29.8 \\
\hline PRPH2 & NM_000322.4:c.512T > G & p.Phe171Cys & 0 & 0 & 4 & 27.3 \\
\hline RP1L1 & NM_178857.5:c.1024_1026delinsCTCCT & p.Arg342LeufsTer22 & 0 & 0 & 4 & 22 \\
\hline RP1L1 & NM_178857.5:c.196G > C & p.Asp66His & 0 & 0 & 3 & 26.6 \\
\hline $\mathrm{KCNV} 2^{3}$ & NM_133497.3:c.-759_*57289del & p.? & 0 & 0 & 5 & \\
\hline KCNV2 ${ }^{1}$ & NM_133497.3:c.1096del & p.Val366TrpfsTer88 & 0 & 0 & 4 & 13.41 \\
\hline$R G R$ & NM_002921.3:c.236G > A & p.Arg79His & 0.0032 & 0.0141 & 3 & 37 \\
\hline BEST1 & NM_004183.3:c.907G > T & p.Asp303Tyr & 0 & 0 & 5 & 28.5 \\
\hline CNGB1 & NM_001297.4:c.2662G > A & p.Ala888Thr & 0.0225 & 0.1145 & 3 & 18.28 \\
\hline CNGB1 & NM_001297.4:c.1658C > A & p.Ala553Glu & 0.0004 & 0.0009 & 3 & 21.1 \\
\hline GUCY2D & NM_000180.3:c.929C > A & p.Thr310Asn & 0 & 0 & 3 & 24.5 \\
\hline RS1 & NM_000330.3:c.209G > A & p.Gly70Asp & 0 & 0 & 4 & 26.7 \\
\hline RS1 & NM_000330.3:c.150G > A & p.Trp50Ter & 0 & 0 & 5 & 35 \\
\hline$R S 1^{4}$ & NM_000330.3:c.53-717_78 + 262del & $\begin{array}{l}\text { p.Ala18_Glu26delinsGluProGlyGlnHisSer } \\
\text { LysThrLeu }\end{array}$ & r & 0 & 5 & \\
\hline$R P G R$ & NM_001034853.1:c.2819_2838dup & p.Glu947LysfsTer149 & 0 & 0 & 3 & 22.4 \\
\hline
\end{tabular}

${ }^{1}$ the variant has been found in 2 unrelated probands. ${ }^{2}$ size of the deletion: 3999-4033 bp (NC_000001.10:g.(94507656_94507700)_ (94511700_94511710)del). ${ }^{3}$ size of the deletion: 70,036 bp (NC_000009.11:g.2716981_2787016del). ${ }^{4}$ size of the deletion: 1005 bp (NC_000023.10:g.18675498_18676502del).

\section{Discussion}

We have presented a targeted sequencing approach based on LR PCR products that is flexible, versatile, and cost-effective. Primers for 124 LR PCRs to cover 35 IRD-associated loci have been established. The method has been validated with 108 molecularly diagnosed IRD cases. All previously identified variants could be verified, corresponding to $100 \%$ sensitivity. The target regions to be sequenced may be personalized according to the clinical phenotype and family history, so that costs can be reduced compared to standard genetic testing.

Although the method provides the most complete coverage of target loci (Figure 1, Figure S1 in the Supplementary Materials), several intronic regions could not be amplified ( $20 \mathrm{~kb}$ out of $1815 \mathrm{~kb}, 0.6 \%$ ). Therefore, few loci (CRB1, EFEMP1, IMPG1, CNGB3, and TIMP3) have minor gaps in coverage. Moreover, whilst the method is very sensitive to deletions that lie within the amplicons, it is not able to detect deletions spanning primer- 
binding regions. In this case, ADO would occur, and the assay would not show any sign of the $\mathrm{CNV}$ other than lower PCR output and the fact that affected regions display exclusively homozygous-appearing variants.

It is not possible to eliminate the risk of ADO in any PCR; however, we did not observe any such events. Homozygous-appearing regions in non-consanguineous families should warrant caution. A final limitation of the method is the need for high molecular weight DNA as a template.

Since the sequencing targets are selected based on clinical phenotype and family history, this method is highly dependent on precise clinical assessment. Close collaboration between the molecular and the clinical diagnostics teams is therefore vital.

The method was used as a first-tier assay to sequence a subpanel of the 35 loci, selected based on clinical diagnosis, in 94 IRD patients (mostly MD) that did not undergo genetic testing previously. Additionally, LR PCR-based sequencing was used as a second-tier assay to discover "second hits" in 25 IRD patients of the missing heritability cohort. These strategies resulted in the identification of likely pathogenic variants in 69 patients of the 119 (58.0\%). Published deep-intronic variants in $A B C A 4$ contributed to the diagnosis of 4 probands (3.4\%).

Variants in $A B C A 4, P R P H 2$, and BEST1 alone explained retinal disease in $60.7 \%$ of the MD cohort, similar to previously published results (57\%) [13]. Even more striking are the results for the STGD sub-cohort, where variants in ABCA4 and PRPH2 were found to be the likely cause of disease in $76.8 \%$ of probands (Figure 3 ). For this reason, we envision our method to be particularly applicable to diseases with low genetic heterogeneity (such as STGD), and as part of a tiered genetic testing strategy to reduce the number of more costly assays (such as WES) for more genetically heterogeneous diseases (such as unspecified $\mathrm{MD}$ and Leber congenital amaurosis). In our study, use of a tiered strategy composed of LR PCR sequencing of $A B C A 4, P R P H 2$, and BEST1, followed by WES for the remaining undiagnosed samples, in the MD cohort would have saved $34 \%$ in material costs. A similar system was previously found to be more sensitive and less expensive than standard WES analysis in one of the largest IRD cohorts yet reported [12].

Furthermore, the protocol can be useful in analyzing challenging regions that are typically not covered by other methods, such as RPGR's exon ORF15. It has been shown previously that NGS of a LR PCR over this region provides good coverage and we have developed a secondary data analysis pipeline to improve sensitivity and specificity $[28,29]$. This strategy permitted the identification of a novel 20 bp insertion (NM_001034853.1:c.2819_2838 dup, Table 3, Table A1) that was not detected by standard analysis pipelines.

As demonstrated by the examples of the $A B C A 4, R P 1, R S 1$, and KCNV2 deletions, the protocol can be adapted easily to characterize the breakpoints of identified CNVs. Even though unambiguous breakpoint characterization was not possible for the $A B C A 4$ deletion, sequencing revealed the deletion to be flanked by two Alu elements and a $10 \mathrm{bp}$ microhomology sequence. The two flanking Alu elements are characterized by variants that increase their homologies, which is suggestive of a gene conversion event [30]. Since the likelihood of these events is indirectly correlated with the distance of the elements, it may be secondary to the deletion event [30].

As a proof of concept, we showed that finalized LR libraries can be spiked into an exome library to either enhance coverage of poorly captured exonic regions (such as RPGR's exon ORF15) or to obtain coverage of otherwise uncaptured regions (such as $A B C A 4^{\prime}$ 's introns) (Figure S2 in the Supplementary Materials).

Finally, the method can facilitate chromosomal phasing. It allows for segregation analysis of multiple variants on the same locus in a single experiment, when samples from family members are available. Moreover, when family members are not available for testing, read phasing based on the LR PCR sequencing data of the index patient might confirm or exclude compound heterozygosity. However, this depends on the density of heterozygous informative variants in the region of interest (Figure 2). 
The method may also be beneficial for other Mendelian diseases, such as CFTR-related diseases, Tay-Sachs disease, Marfan syndrome, and tuberous sclerosis.

\section{Materials and Methods}

\subsection{Patients and Family Members}

Unrelated probands $(\mathrm{N}=227)$ were referred to us for genetic testing from different eye clinics with a clinical diagnosis and information about family history. Samples $(\mathrm{N}=166)$ from 66 families were available for segregation analysis. Written informed consent was obtained from all probands and family members included in this study, which was conducted in accordance with the 2013 Declaration of Helsinki.

The probands included in this study were assigned to one of three groups: (i) validation cohort (molecular diagnosis previously established by using WES, $n=108$ ), (ii) missing heritability cohort (no molecular diagnosis established with previous WES analysis, $n=25$ ), (iii) probands without previous genetic testing $(n=94)$.

\subsection{Genomic DNA}

The majority of genomic DNA (gDNA) samples $(n=204)$ were extracted in duplicate with the automated chemagic MSM I system according to the manufacturer's specifications (PerkinElmer Chemagen Technologie GmbH, Baesweiler, Germany). The remaining gDNA samples $(n=23)$ were extracted at external labs and sent to us. Genomic DNA integrity and concentration were evaluated on a Nanodrop instrument (Life Technologies, Carlsbad, CA, USA). Aliquots of gDNA were diluted to $10 \mathrm{ng} / \mu \mathrm{L}$ with $\mathrm{ddH}_{2} \mathrm{O}$ for use in PCRs.

\subsection{Long-Range PCR primers}

Primers for LR PCR were designed on NCBI's Primer-Blast to be 28 bp (range 26-30) long and to have a melting temperature $(\mathrm{Tm})$ of $67^{\circ} \mathrm{C}$ (range $65-68{ }^{\circ} \mathrm{C}$ ) under default settings [31]. The size of PCR products depended on the target locus and ranged from 4.3 to $19.9 \mathrm{~kb}$ (mean size $=15.8 \mathrm{~kb}$, median size $=17.6 \mathrm{~kb}$ ). Primers for a total of 124 PCRs to amplify the following IRD-associated loci were validated (synthesized by Microsynth AG, Balgach, Switzerland): PPT1, ABCA4, CRB1, PCARE (C2orf71), EFEMP1, IMPG2, PROM1, MFSD8, CTNNA1, GUCA1A, GUCA1B, PRPH2, IMPG1, ELOVL4, DHS6S1, RP1L1, RP1, CNGB3, KCNV2, ATOH7, PDE6C, BEST1, C1QTNF5, PDE6H, RDH5, OTX2, NR2E3, RLBP1, GUCY2D, FSCN2, RAX2, TIMP3, RS1, RPGR, and RP2. The validated primers are listed in Table 22 in the Supplementary Materials.

\subsection{Long-Range PCR}

The LR PCR products used in this study were generated using Takara's long and accurate (LA) Taq polymerases (Takara Bio, Kusatsu, Japan) according to the following PCR mixture: $30 \mu \mathrm{L}$ total reaction volume, $11.5 \mu \mathrm{L}$ of $\mathrm{ddH}_{2} \mathrm{O}, 50 \mathrm{ng}$ of template gDNA, $3 \mu \mathrm{L}$ of $10 \times$ LA PCR Buffer II ( $\mathrm{Mg}^{2+}$ plus), $3 \mu \mathrm{L}$ of $10 \times$ Solution S (Solis BioDyne, Tartu, Estonia), $4.8 \mu \mathrm{L}$ of deoxynucleoside triphosphates (dNTPs) Mixture ( $2.5 \mathrm{mM}$ each), $1.2 \mu \mathrm{L}$ of each primer $(10 \mathrm{mM})$, and $0.3 \mu \mathrm{L}$ of Takara LA Taq (5 units/ $\mu \mathrm{L})$. Reactions were performed on a Veriti thermal cycler (Applied Biosystems, Foster City, CA, USA) according to two-step PCR conditions: $94{ }^{\circ} \mathrm{C}$ for $2 \mathrm{~min}, 35$ cycles of $98^{\circ} \mathrm{C}$ for $10 \mathrm{~s}$ and $68^{\circ} \mathrm{C}$ for $12 \mathrm{~min}$, followed by $72{ }^{\circ} \mathrm{C}$ for $10 \mathrm{~min}$, and hold at $4{ }^{\circ} \mathrm{C}$.

\subsection{PCR Quality Control and Pooling}

The expected size of amplicons was confirmed by electrophoresis on $0.6 \%$ agarose gels (run at $60 \mathrm{~V}$ ) and $1 \mu \mathrm{L}$ of the reaction mixture was used to measure the amplicon concentration with the Qubit dsDNA High-Sensitivity Assay kit (ThermoFisher, Waltham, MA, USA).

All amplicons that would be sequenced with the same index sequence (either all PCRs of a specific proband or non-overlapping amplicons of different probands) were diluted to $10 \mathrm{ng} / \mu \mathrm{L}$ in $1 \times$ Tris-EDTA (TE) buffer (Integrated DNA Technologies, Coralville, IA, USA). 
The volume of each diluted PCR added to the pool was proportional to its size, for a final pool of at least $130 \mu \mathrm{L}$ in total volume.

\subsection{Library Construction and Sequencing}

Each pool was sheared on a Covaris M220 (Covaris, Woburn, MA, USA) in a $130 \mu \mathrm{L}$ Covaris Adaptive Focused Acoustics (AFA) microtube (Covaris, Woburn, MA, USA) to a target size of $\sim 350-400 \mathrm{bp}$, with the following settings: $50 \mathrm{~W}$ peak incident power, $20 \%$ duty factor, 200 cycles per burst, $65 \mathrm{~s}$ treatment time.

Successful fragmentation was checked by running $1 \mu \mathrm{L}$ of the sheared pool with a Bioanalyzer High-Sensitivity DNA kit on a Bioanalyzer 2100 instrument (Agilent Technologies, Santa Clara, CA, USA).

The validated pools were then processed with the TruSeq DNA Nano Low-Throughput Library Prep kit and TruSeq DNA Single Index Set A and B, according to the manufacturer's protocol (Illumina, San Diego, CA, USA).

Molarities of the libraries were calculated and diluted to a $4 \mathrm{nM}$ working concentration. The different libraries that were to be sequenced together (with different indexes) were pooled proportionally to their total genomic target size. Subsequently, these pools were denatured with $0.2 \mathrm{~N} \mathrm{NaOH}$ and loaded into a MiSeq Reagent Kit V2 (300 cycles) cartridge, according to the manufacturer's recommendations (Illumina, San Diego, CA, USA). Pairedend sequencing $(2 \times 151$ cycles) was performed on a MiSeq instrument (Illumina, San Diego, CA, USA).

A detailed step-by-step protocol is provided in the Supplementary Materials (Text S1).

\subsection{ABCA4 Capture Sequencing}

Custom-capture probes (xGen Lockdown Probe Pools) were designed for the $A B C A 4$ locus by IDT (Integrated DNA Technologies, Coralville, IA, USA). Genomic DNA libraries were constructed according to the ThruPLEX DNA-seq 96D kit protocol (Takara Bio, Kusatsu, Japan). Libraries were pooled equimolarly for a total of $1600 \mathrm{ng}$ of DNA. Subsequently, the $A B C A 4$ capture probes were used according to the manufacturer's protocol to enrich the $A B C A 4$ locus (Integrated DNA Technologies, Coralville, IA, USA). The resulting libraries were sequenced on a MiSeq according to manufacturer's recommendations (Illumina, San Diego, CA, USA).

\subsection{Whole-Exome Sequencing}

WES was performed for 152 probands: 23 of them underwent WES in an external facility on an Illumina HiSeq instrument (AtlasBiolabs, Berlin, Germany) or on a SOLiD 5500 xl system (CeGat, Tübingen, Germany), whilst 129 probands were sequenced in-house on a NextSeq 550 (Illumina, San Diego, CA, USA). Of the 129 in-house WES, 31 were captured using the Nextera Rapid Capture Exome kit (Illumina, San Diego, CA, USA), 65 with the TruSeq Exome kit (Illumina, San Diego, CA, USA), and 33 with the xGen Exome Research Panel (Integrated DNA Technologies, Coralville, IA, USA), according to the manufacturers' protocols.

\subsection{Exome Spike-In Applications}

To assess the feasibility of spike-in to WES experiments to enhance coverage of regions of interest, we tested two alternatives: by adding the custom xGen Lockdown Probe pool for the $A B C A 4$ locus to the TruSeq Exome kit, capturing probes mix before hybridization, or by adding the processed LR PCR libraries just before final library denaturation.

An aliquot of the xGen Lockdown Probes was diluted to a concentration of $85.5 \mathrm{aM}$ and a total of $250 \mathrm{amol}$ were added to the TruSeq Exome capture mix for spike-in. Conversely, for the LR libraries spike-in, the amount of library to be added was calculated based on the ratio of the total LR library target regions and the WES target region. 


\subsection{Sequencing Data Analysis}

Illumina sequencing data was aligned to the human reference genome hg19 with Burrows-Wheeler Aligner (BWA), and variant calling was performed by Genome Analysis Toolkit (GATK) [32,33]. The resulting Variant Call Format files (VCFs) were annotated with Alamut Batch v1.8 (SophiaGenetics, Lausanne, Switzerland) using a gene list corresponding either to the loci present in the RetNet database $(n=276)$ for WES data, or to the target loci for LR PCRs data. CNVs analysis on target-capture sequencing data ( $A B C A 4$ capture and WES results) was performed using panelcn.mops [34] and the SeqNext module of Sequence Pilot v5.2 (JSI medical systems, Ettenheim, Germany).

LR PCR sequencing data of RPGR's exon ORF15 was assembled de novo using SPAdes and the resulting contig was aligned to the reference sequence, as previously described $[29,35]$.

\subsection{CNV Validation and Breakpoints Characterization}

MLPA (MRC Holland, Amsterdam, The Netherlands) was used to validate candidate CNVs identified by panelcn.mops and/or SeqNext in ABCA4, BEST1, GUCY2D, and RPGRIP1 and to screen for CNVs in ABCA4, BEST1, and PRPH2.

Deletions encompassing exons 20 through 22 of $A B C A 4$, exon 2 of $R S 1$, exons 2 through 4 of $R P 1$, and the entire KCNV2 gene were identified by panelcn.mops and SeqNext or by comparison of coverage plots. These deletions were verified and characterized by LR PCR. The primers used are listed in Table S3 in the Supplementary Materials. Briefly, primers were designed based on the estimated breakpoints location, LR PCR was performed, and the amplicon was sequenced as described above (see amplicons pool library construction and sequencing). In addition, breakpoints were confirmed by Sanger sequencing (primers in Table S4 in the Supplementary Materials).

To narrow down the breakpoint region of the KCNV2 deletion, an Infinium CytoSNP850K BeadChip array analysis was performed according to the manufacturer's protocol (Illumina, San Diego, CA, USA).

The $A B C A 4$ deletion was further characterized and refined by TLA (Cergentis, Utrecht, The Netherlands).

\subsection{Chromosomal Phasing}

Segregation analysis was performed if samples from family members were available, either by Sanger sequencing (primers on Table S4 in the Supplementary Materials) or by LR PCR sequencing, as described above.

Alternatively, when no family members were available for testing, read phasing was performed. For this, reads in the Binary Alignment Map (BAM) file were visually inspected for informative heterozygous variants between the two putative compound heterozygous candidate variants (Figure 2).

Supplementary Materials: The following are available online at https://www.mdpi.com/1422-0 067/22/4/1508/s1, Figure S1: Long-range PCRs panel coverage results, Figure S2: Exome spike-in proof of concept, Text S1: Detailed long-range PCR sequencing protocol, Table S1: Rare variants found in undiagnosed cases, Table S2: Long-range PCR primers, Table S3: Long-range PCR primers for breakpoint characterization, Table S4: Sanger sequencing primers.

Author Contributions: Conceptualization, J.M., S.K., and W.B.; methodology, J.M.; software, J.M. and S.K.; validation, J.M., L.B., and A.M.; formal analysis, J.M.; investigation, J.M., L.B., S.F., F.K.P., J.V.M.H., and C.G.-K.; resources, W.B. and C.G.-K.; data curation, J.M.; writing-original draft, J.M.; writing—review and editing, J.M., S.K., F.K.P., J.V.M.H., C.G.-K., and W.B.; visualization, J.M.; supervision, S.K. and W.B.; project administration, J.M. and W.B.; funding acquisition, J.M. and W.B. All authors have read and agreed to the published version of the manuscript.

Funding: This research was funded by Velux Stiftung, grant number 1371.

Institutional Review Board Statement: The study was conducted according to the guidelines of the Declaration of Helsinki, and approval for genetic testing in human patients was awarded to 
the Institute of Medical Molecular Genetics by the Federal Office for Public Health (FOPH) in Switzerland.

Informed Consent Statement: Informed consent was obtained from all subjects involved in the study.

Data Availability Statement: The data presented in this study are available in the article and the supplementary materials. Raw data are not publicly available due to data protection regulations.

Acknowledgments: We are grateful to all probands and family members who participated in this study. Moreover, we would like to thank all referring physicians, and Dres. Angela Bahr and Istvan Magyar for their support. Finally, we appreciate the help provided by Cergentis B.V.

Conflicts of Interest: The authors declare no conflict of interest. The funders had no role in the design of the study; in the collection, analyses, or interpretation of data; in the writing of the manuscript, or in the decision to publish the results.

\section{Appendix A}

Reported here are the genetic findings for the three cohorts discussed in the main text: Validation cohort $(n=108)$, no previous genetic testing cohort $(n=94)$, and missing heritability cohort $(n=25)$. Table A1 summarizes the likely pathogenic variants identified in the validation cohort. Similarly, Table A2 highlights the likely pathogenic variants found in molecularly diagnosed patients included in the cohort without previous genetic testing. Finally, Table A3 reports the genetic findings in molecularly diagnosed patients of the missing heritability cohort. 


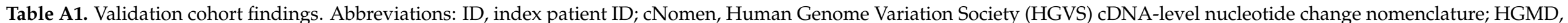

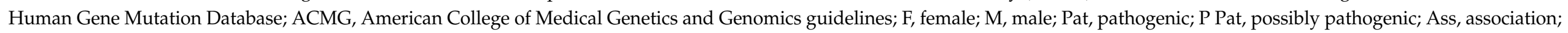
Ref, reference; NA, not applicable; $S$, segregation; R, read phasing.

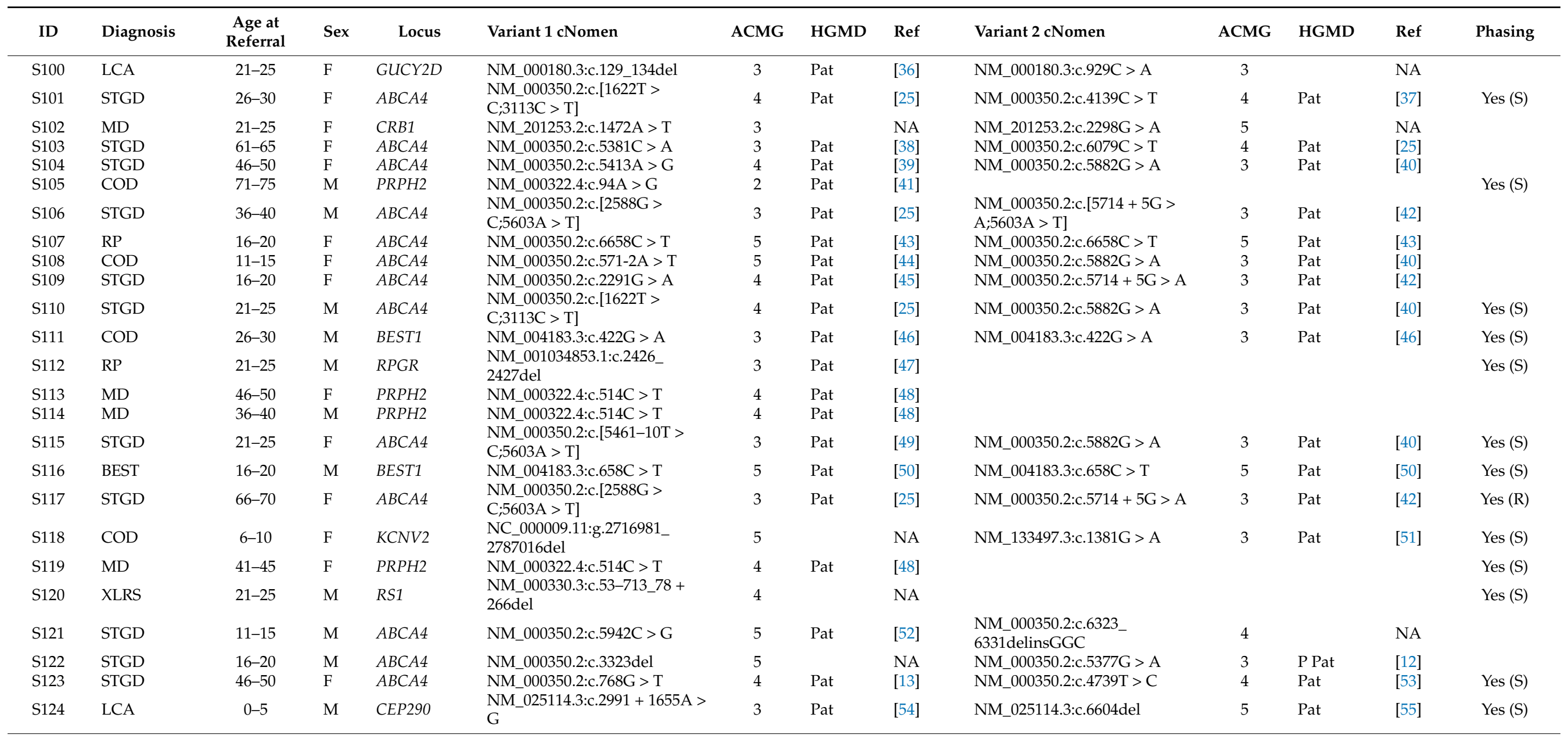


Table A1. Cont.

\begin{tabular}{|c|c|c|c|c|c|c|c|c|c|c|c|c|c|}
\hline ID & Diagnosis & $\begin{array}{l}\text { Age at } \\
\text { Referral }\end{array}$ & Sex & Locus & Variant 1 cNomen & ACMG & HGMD & Ref & Variant 2 cNomen & ACMG & HGMD & Ref & Phasing \\
\hline S125 & STGD & $16-20$ & $\mathrm{~F}$ & $A B C A 4$ & $\begin{array}{l}\text { NM_000350.2:c.[1610G > } \\
\text { A;5603A > T] }\end{array}$ & 1 & Pat & [56] & NM_000350.2:c.3523-1G > A & 5 & Pat & [21] & Yes (S) \\
\hline S126 & STGD & $26-30$ & M & $A B C A 4$ & NM_000350.2:c.5882G > A & 3 & Pat & [40] & NM_000350.2:c.6088C > T & 5 & Pat & [37] & \\
\hline S127 & ML & $46-50$ & M & PRPH2 & NM_000322.4:c.514C > T & 4 & Pat & [48] & & & & & \\
\hline S128 & $\mathrm{RP}$ & $6-10$ & M & $R P 2$ & NM_006915.2:c.884-9T > A & 3 & Pat & [57] & & & & & Yes (S) \\
\hline S129 & STGD & $41-45$ & $\mathrm{~F}$ & $A B C A 4$ & NM_000350.2:c.2291G > A & 4 & Pat & [45] & NM_000350.2:c.5381C > A & 3 & Pat & [38] & \\
\hline $\mathrm{S} 130$ & COD & $21-25$ & $\mathrm{~F}$ & CNGB3 & NM_019098.4:c.1148del & 5 & Pat & [58] & NM_019098.4:c.1148del & 5 & Pat & [58] & \\
\hline S131 & BEST & $16-20$ & M & BEST1 & NM_004183.3:c.728C > T & 4 & Pat & [59] & & & & & \\
\hline S133 & MD & $21-25$ & $\mathrm{~F}$ & PRPH2 & NM_000322.4:c.514C > T & 4 & Pat & {$[48]$} & & & & & Yes (S) \\
\hline S134 & MD & $31-35$ & $\mathrm{~F}$ & BEST1 & NM_004183.3:c.584C > T & 3 & Pat & [61] & NM_004183.3:c.584C > T & 3 & Pat & [61] & \\
\hline S135 & MD & $36-40$ & M & PRPH2 & NM_000322.4:c.514C > T & 4 & Pat & [48] & & & & & \\
\hline S136 & MD & $46-50$ & $\mathrm{M}$ & PRPH2 & NM_000322.4:c.514C > T & 4 & Pat & [48] & & & & & \\
\hline S137 & BEST & $26-30$ & $\mathrm{M}$ & BEST1 & NM_004183.3:c.-37 + 1G > T & 5 & Pat & [62] & NM_004183.3:c.-37 + 1G > T & 5 & Pat & [62] & Yes (S) \\
\hline S138 & CRD & $36-40$ & M & PROM1 & NM_006017.2:c.380G > A & 3 & Pat & [63] & NM_006017.2:c.380G > A & 3 & Pat & [63] & \\
\hline S139 & $\mathrm{RD}$ & $41-45$ & F & $A B C A 4$ & $\begin{array}{l}\text { NM_000350.2:c. }[52 \mathrm{C}>\mathrm{T} ; 5603 \mathrm{~A} \\
>\mathrm{T}]\end{array}$ & 4 & Pat & [64] & $\begin{array}{l}\text { NM_000350.2:c. }[52 \mathrm{C}>\mathrm{T} ; 5603 \mathrm{~A} \\
>\mathrm{T}]\end{array}$ & 4 & Pat & [64] & \\
\hline S140 & LCA & $0-5$ & $\mathrm{~F}$ & CRB1 & NM_201253.2:c.2230C > T & 5 & Pat & [65] & NM_201253.2:c.2230C > T & 5 & Pat & [65] & \\
\hline S141 & CRD & $31-35$ & M & $A B C A 4$ & NM_000350.2:c.1804C > T & 5 & Pat & [37] & NM_000350.2:c.5882G > A & 3 & Pat & [40] & \\
\hline S142 & LCA & $0-5$ & $\mathrm{~F}$ & CRB1 & NM_201253.2:c.547T >C & 3 & Pat & [63] & NM_201253.2:c.2687G > C & 4 & Pat & [63] & \\
\hline S144 & MD & $31-35$ & M & $A B C A 4$ & NM_000350.2:c.1957C > T & 5 & Pat & [45] & NM_000350.2:c.5882G > A & 3 & Pat & [40] & \\
\hline S145 & $\mathrm{RP}$ & $36-40$ & $\mathrm{~F}$ & $A B C A 4$ & NM_000350.2:c.4873C > T & 3 & Pat & [63] & NM_000350.2:c.4873C > T & 3 & Pat & [63] & \\
\hline S146 & MD & $26-30$ & $\mathrm{~F}$ & $A B C A 4$ & $\begin{array}{l}\text { NM_000350.2:c.[1610G > } \\
\text { A;5603A > T] }\end{array}$ & 1 & Pat & [56] & $\begin{array}{l}\text { NM_000350.2:c.[5461-10T > } \\
\text { C;5603A > T] }\end{array}$ & 3 & Pat & [49] & Yes (S) \\
\hline S147 & CRD & $21-25$ & M & $A B C A 4$ & $\begin{array}{l}\text { NM_000350.2:c.[5461-10T > } \\
\text { C;5603A > T] }\end{array}$ & 3 & Pat & [49] & NM_000350.2:c.5882G > A & 3 & Pat & [40] & \\
\hline S148 & STGD & $46-50$ & M & $A B C A 4$ & NM_000350.2:c.4873C > T & 3 & Pat & [63] & NM_000350.2:c.5714 + 5G > A & 3 & Pat & [42] & \\
\hline S149 & $\mathrm{RD}$ & $21-25$ & M & $A B C A 4$ & NM_000350.2:c.4462T > C & 5 & Pat & [37] & NM_000350.2:c.5882G > A & 3 & Pat & [40] & \\
\hline S150 & STGD & $31-35$ & $\mathrm{~F}$ & $A B C A 4$ & NM_000350.2:c.2932G > A & 4 & $\begin{array}{l}\mathrm{P} \\
\text { Pat }\end{array}$ & [12] & NM_000350.2:c.5882G > A & 3 & Pat & [40] & \\
\hline S151 & $\mathrm{RP}$ & $11-15$ & $\mathrm{~F}$ & $A B C A 4$ & NM_000350.2:c.1988G > A & 5 & Pat & [45] & NM_000350.2:c.2160 + 1G > T & 5 & Pat & [63] & Yes (R) \\
\hline S152 & STGD & $16-20$ & $\mathrm{~F}$ & $A B C A 4$ & NM_000350.2:c.1957C > T & 5 & Pat & [45] & NM_000350.2:c.5691G > T & 3 & & NA & Yes (S) \\
\hline S153 & STGD & $31-35$ & $\mathrm{~F}$ & ELOVL4 & NM_022726.3:c.810C > G & 5 & Pat & [66] & & & & & \\
\hline S154 & MD & $31-35$ & M & CRB1 & NM_201253.2:c.498_506del & 3 & Pat & [67] & NM_201253.2:c.2290C > T & 4 & Pat & [68] & Yes (S) \\
\hline S155 & $\mathrm{RP}$ & $51-55$ & M & $R P 1$ & NM_006269.1:c.2613dup & 5 & Pat & [69] & & & & & Yes (S) \\
\hline S156 & $\mathrm{RP}$ & $21-25$ & M & $R P G R$ & $\begin{array}{l}\text { NM_001034853.1:c.2586_ } \\
\text { 2587del }\end{array}$ & 3 & Pat & [70] & & & & & \\
\hline
\end{tabular}


Table A1. Cont.

\begin{tabular}{|c|c|c|c|c|c|c|c|c|c|c|c|c|c|}
\hline ID & Diagnosis & $\begin{array}{c}\text { Age at } \\
\text { Referral }\end{array}$ & Sex & Locus & Variant 1 cNomen & ACMG & HGMD & Ref & Variant 2 cNomen & ACMG & HGMD & Ref & Phasing \\
\hline S157 & $\mathrm{RP}$ & $11-15$ & $\mathrm{~F}$ & $R P G R$ & $\begin{array}{l}\text { NM_001034853.1:c.2008_ } \\
\text { 2017del }\end{array}$ & 4 & Pat & [63] & & & & & Yes (S) \\
\hline S158 & MD & $36-40$ & $\mathrm{M}$ & PRPH2 & NM_000322.4:c.514C > T & 4 & Pat & [48] & & & & & \\
\hline S159 & $\mathrm{RD}$ & NA & $\mathrm{M}$ & $A B C A 4$ & NM_000350.2:c.4352 + 1G > A & 5 & Pat & [71] & NM_000350.2:c.4919G > A & 4 & Pat & [72] & \\
\hline S160 & STGD & $51-55$ & $\mathrm{~F}$ & PRPH2 & NM_000322.4:c.514C > T & 4 & Pat & [48] & & & & & \\
\hline S161 & STGD & $46-50$ & $\mathrm{~F}$ & $A B C A 4$ & NM_000350.2:c.2401G > A & 3 & $\begin{array}{l}\mathrm{P} \\
\text { Pat }\end{array}$ & [73] & NM_000350.2:c.5381C > A & 3 & Pat & [38] & \\
\hline S162 & STGD & $26-30$ & M & $A B C A 4$ & NM_000350.2:c.5882G > A & 3 & Pat & [40] & NM_000350.2:c.6122G > A & 4 & Pat & [74] & \\
\hline S164 & STGD & $41-45$ & $\mathrm{~F}$ & $A B C A 4$ & NM_000350.2:c.5329A > T & 3 & $\begin{array}{l}\mathrm{P} \\
\text { Pat }\end{array}$ & [75] & $\begin{array}{l}\text { NM_000350.2:c.[5461-10T > } \\
\text { C;5603A > T] }\end{array}$ & 3 & Pat & [49] & Yes (S) \\
\hline S165 & STGD & $56-60$ & $\mathrm{~F}$ & $A B C A 4$ & NM_000350.2:c.4958G > A & 3 & & NA & NM_000350.2:c.5882G > A & 3 & Pat & [40] & \\
\hline S166 & $\mathrm{RP}$ & $21-25$ & M & $R P G R$ & $\begin{array}{l}\text { NM_001034853.1:c.2236_ } \\
\text { 2237del }\end{array}$ & 4 & Pat & {$[47]$} & & & & & \\
\hline S167 & BEST & $51-55$ & M & BEST1 & NM_004183.3:c.388C > A & 4 & Pat & [76] & NM_004183.3:c.638A > G & 4 & Pat & {$[77]$} & \\
\hline S168 & STGD & $26-30$ & $\mathrm{~F}$ & $A B C A 4$ & NM_000350.2:c.3179A > C & 4 & & NA & NM_000350.2:c.3179A > C & 4 & & NA & \\
\hline S169 & STGD & $6-10$ & $\mathrm{M}$ & $A B C A 4$ & NM_000350.2:c.160T > G & 4 & Pat & [78] & NM_000350.2:c.160T > G & 4 & Pat & [78] & Yes (S) \\
\hline S170 & BEST & $6-10$ & $\mathrm{~F}$ & BEST1 & NM_004183.3:c.907G > T & 4 & & $\mathrm{NA}$ & & & & & Yes (S) \\
\hline S171 & STGD & $41-45$ & $\mathrm{M}$ & ELOVL4 & NM_022726.3:c.810C > G & 5 & Pat & [66] & & & & & \\
\hline S172 & STGD & $26-30$ & $\mathrm{M}$ & $A B C A 4$ & NM_000350.2:c.5882G > A & 3 & Pat & [40] & NM_000350.2:c.6282 + 1G >C & 5 & Pat & [79] & Yes (S) \\
\hline S174 & STGD & $36-40$ & $\mathrm{~F}$ & $A B C A 4$ & NM_000350.2:c.1742C > A & 3 & & $\mathrm{NA}$ & NM_000350.2:c.5882G > A & 3 & Pat & [40] & \\
\hline S175 & $\mathrm{RP}$ & $11-15$ & $\mathrm{M}$ & $R P G R$ & $\begin{array}{l}\text { NM_001034853.1:c.2819_ } \\
\text { 2838dup }\end{array}$ & 3 & & NA & & & & & \\
\hline S176 & STGD & $21-25$ & $\mathrm{~F}$ & $A B C A 4$ & NM_000350.2:c.4609del & 4 & & NA & NM_000350.2:c.5882G > A & 3 & Pat & [40] & \\
\hline S177 & XLRS & $41-45$ & $\mathrm{M}$ & RS1 & NM_000330.3:c.304C > T & 4 & Pat & [81] & & & & & \\
\hline S178 & STGD & $16-20$ & M & $A B C A 4$ & NM_000350.2:c.4383G >C & 3 & & NA & NM_000350.2:c.5882G > A & 3 & Pat & [40] & Yes (S) \\
\hline S179 & STGD & $21-25$ & $\mathrm{~F}$ & $A B C A 4$ & $\begin{array}{l}\text { NM_000350.2:c.[3322C > } \\
\text { T;6320G > A] }\end{array}$ & 4 & Pat & [82] & NM_000350.2:c.5882G > A & 3 & Pat & [40] & Yes (S) \\
\hline S180 & STGD & $46-50$ & M & ELOVL4 & NM_022726.3:c.810C > G & 5 & Pat & [66] & & & & & \\
\hline S181 & CRD & $31-35$ & $\mathrm{~F}$ & $A B C A 4$ & NM_000350.2:c.727_728dup & 5 & & NA & NM_000350.2:c.735T > G & 5 & Pat & [83] & Yes $(\mathrm{R})$ \\
\hline S182 & STGD & $26-30$ & $\mathrm{M}$ & $A B C A 4$ & NM_000350.2:c.5413A > G & 4 & Pat & [39] & NM_000350.2:c.6428T > A & 4 & & NA & Yes (S) \\
\hline S183 & STGD & $51-55$ & $\mathrm{~F}$ & CDHR1 & NM_033100.3:c.783G > A & 1 & Pat & [13] & NM_033100.3:c.783G > A & 1 & Pat & [13] & \\
\hline S184 & STGD & $41-45$ & $\mathrm{~F}$ & $A B C A 4$ & NM_000350.2:c.5461-6T > C & 3 & & NA & NM_000350.2:c.5882G > A & 3 & Pat & [40] & Yes (S) \\
\hline S185 & $\mathrm{RP}$ & $6-10$ & M & SNRNP200 & NM_014014.4:c.1634G > A & 3 & Pat & [84] & NM_014014.4:c.1634G > A & 3 & Pat & [84] & \\
\hline
\end{tabular}


Table A1. Cont.

\begin{tabular}{|c|c|c|c|c|c|c|c|c|c|c|c|c|c|}
\hline ID & Diagnosis & $\begin{array}{c}\text { Age at } \\
\text { Referral }\end{array}$ & Sex & Locus & Variant $1 \mathrm{cNomen}$ & ACMG & HGMD & Ref & Variant 2 cNomen & ACMG & HGMD & Ref & Phasing \\
\hline S186 & CRD & $16-20$ & $\mathrm{~F}$ & PROM1 & NM_006017.2:c.1142-1G > A & 5 & $\begin{array}{l}\text { P } \\
\text { Pat }\end{array}$ & [13] & NM_006017.2:c.1142-1G > A & 5 & P Pat & [13] & Yes (S) \\
\hline S187 & MD & $16-20$ & $\mathrm{~F}$ & $A B C A 4$ & NM_000350.2:c.5018 + 2T >C & 5 & Pat & [85] & \multirow{2}{*}{$\begin{array}{l}\text { NM_000350.2:c.5018 + 2T > C } \\
\text { NM_000350.2:c. }[2588 G> \\
\text { C;5603A > T] }\end{array}$} & 5 & Pat & [85] & \\
\hline S188 & STGD & $26-30$ & M & $A B C A 4$ & NM_000350.2:c.454C > T & 5 & Pat & [86] & & 3 & Pat & {$[25]$} & Yes (S) \\
\hline S189 & $\mathrm{MD}$ & $26-30$ & M & KCNV2 & NM_133497.3:c.1096del & 4 & & NA & NM_133497.3:c.1381G > A & 3 & Pat & [51] & Yes (S) \\
\hline S190 & STGD & $76-80$ & M & $A B C A 4$ & NM_000350.2:c.2041C > T & 5 & Pat & [43] & \multirow{3}{*}{$\begin{array}{l}\text { NM_000350.2:c.5603A > T } \\
\text { NM_019098.4:c.1578 + 1G > A }\end{array}$} & 3 & Ass & [18] & \\
\hline S191 & BEST & $56-60$ & $\mathrm{M}$ & BEST1 & NM_004183.3:c.73C > T & 4 & Pat & [46] & & & & & \\
\hline S193 & BEST & $46-50$ & $\mathrm{M}$ & BEST1 & NM_004183.3:c.653G > A & 4 & Pat & [61] & & & & & \\
\hline S194 & STGD & $76-80$ & $\mathrm{M}$ & $A B C A 4$ & NM_000350.2:c.5714 + 5G > A & 3 & Pat & [42] & \multirow{3}{*}{$\begin{array}{l}\text { NM_000350.2:c.5882G > A } \\
\text { NM_000350.2:c.4328G > A } \\
\text { NM_000350.2:c.[1622T > } \\
\text { C;3113C > T] }\end{array}$} & 3 & Pat & {$[40]$} & \\
\hline S195 & STGD & $46-50$ & $\mathrm{M}$ & $A B C A 4$ & NM_000350.2:c.1846G > A & 4 & Pat & [53] & & 4 & Pat & {$[45]$} & \\
\hline S196 & STGD & $11-15$ & $\mathrm{~F}$ & $A B C A 4$ & NM_000350.2:c.1A > G & 5 & Pat & [88] & & 4 & Pat & [25] & \\
\hline S197 & $\mathrm{RP}$ & $56-60$ & $\mathrm{M}$ & RP1L1 & $\begin{array}{l}\text { NM_178857.5:c.1024_ } \\
\text { 1026delinsCTCCT }\end{array}$ & 4 & & NA & & & & & \\
\hline S198 & $\mathrm{RP}$ & $56-60$ & $\mathrm{~F}$ & $R P 1$ & NM_006269.1:c.2613dup & 5 & Pat & [69] & & & & & \\
\hline S199 & $\mathrm{RP}$ & $61-65$ & $\mathrm{M}$ & PRPH2 & NM_000322.4:c.512T > G & 4 & & NA & & & & & \\
\hline S200 & ML & $76-80$ & $\mathrm{M}$ & EFEMP1 & NM_001039348.2:c.1033C > T & 3 & Pat & [89] & & & & & \\
\hline S201 & $\mathrm{RD}$ & $36-40$ & $\mathrm{M}$ & $A B C A 4$ & NM_000350.2:c.184C > T & 4 & Pat & [21] & NM_000350.2:c.5882G > A & 3 & Pat & [40] & Yes (S) \\
\hline S203 & CRD & $51-55$ & $\mathrm{M}$ & PROM1 & NM_006017.2:c.2476G > C & 3 & & NA & NM_006017.2:c.2476G > C & 3 & & NA & \\
\hline S204 & CRD & $41-45$ & $\mathrm{M}$ & ELOVL4 & NM_022726.3:c.810C > G & 5 & Pat & [66] & & & & & \\
\hline S205 & $\mathrm{RP}$ & $16-20$ & $\mathrm{~F}$ & $R P 1$ & $\begin{array}{l}\text { NM_006269.1:c.-12- } \\
\text { 1431_*286del }\end{array}$ & 4 & Pat & {$[27]$} & $\begin{array}{l}\text { NM_006269.1:c.-12- } \\
\text { 1431_*286del }\end{array}$ & 4 & Pat & {$[27]$} & Yes (S) \\
\hline S206 & $\mathrm{RD}$ & $31-35$ & M & $C R X$ & NM_000554.5:c.118C > T & 4 & Pat & [90] & & & & & \\
\hline S207 & STGD & $16-20$ & $\mathrm{~F}$ & $A B C A 4$ & $\begin{array}{l}\text { NM_000350.2:c.[5461-10T > } \\
\text { C;5603A > T] }\end{array}$ & 3 & Pat & [49] & NM_000350.2:c.5714 + 5G > A & 3 & Pat & [42] & Yes (S) \\
\hline
\end{tabular}




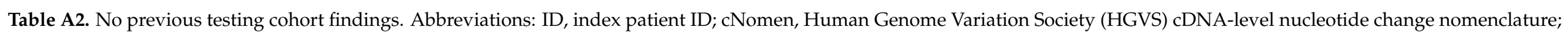

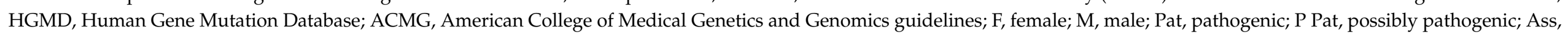
association; Ref, reference; NA, not applicable; $S$, segregation; R, read phasing.

\begin{tabular}{|c|c|c|c|c|c|c|c|c|c|c|c|c|c|}
\hline ID & Diagnosis & $\begin{array}{l}\text { Age at } \\
\text { Referral }\end{array}$ & Sex & Locus & Variant 1 cNomen & ACMG & HGMD & Ref & Variant 2 cNomen & ACMG & HGMD & Ref & Phasing \\
\hline S209 & STGD & $21-25$ & $\mathrm{~F}$ & KCNJ13 & NM_002242.4:c.484C > T & 3 & Pat & [91] & & & & & Yes (S) \\
\hline S210 & ML & $36-40$ & $\mathrm{~F}$ & EFEMP1 & NM_001039348.2:c.1033C > T & 3 & Pat & [89] & & & & & Yes (S) \\
\hline S211 & STGD & $56-60$ & $\mathrm{M}$ & $A B C A 4$ & NM_000350.2:c.3210_3211dup & 5 & Pat & [25] & NM_000350.2:c.5603A > T & 3 & Ass & [18] & \\
\hline S212 & MD & $36-40$ & $\mathrm{M}$ & OPA1 & NM_130837.2:c.1890_1891del & 5 & Pat & [92] & & & & & \\
\hline S213 & CRD & $21-25$ & $\mathrm{M}$ & $A B C A 4$ & NM_000350.2:c.160T > G & 4 & Pat & [78] & NM_000350.2:c.5882G > A & 3 & Pat & [40] & \\
\hline S214 & STGD & $46-50$ & $\mathrm{~F}$ & PRPH2 & NM_000322.4:c.424C > T & 4 & Pat & [93] & & & & & \\
\hline S215 & MD & $36-40$ & $\mathrm{M}$ & $A B C A 4$ & NM_000350.2:c.4139C > T & 4 & Pat & [37] & NM_000350.2:c.5714 + 5G > A & 3 & Pat & [42] & \\
\hline S216 & MD & $46-50$ & $\mathrm{~F}$ & OPA1 & NM_130837.2:c.2987A > C & 4 & & NA & & & & & \\
\hline S218 & STGD & $6-10$ & $\mathrm{~F}$ & $A B C A 4$ & NM_000350.2:c.6731T > A & 3 & & NA & NM_000350.2:c.6731T > A & 3 & & NA & Yes (S) \\
\hline S219 & STGD & $21-25$ & F & $A B C A 4$ & NM_000350.2:c.2401G > A & 3 & $\begin{array}{l}\text { P } \\
\text { Pat }\end{array}$ & [73] & NM_000350.2:c.5018 + 2T >C & 5 & Pat & [85] & \\
\hline S220 & ACHR & $0-5$ & $\mathrm{~F}$ & CNGB3 & NM_019098.4:c.1148del & 5 & Pat & [58] & NM_019098.4:c.1167_1168insC & 4 & & NA & Yes (R) \\
\hline S221 & STGD & $41-45$ & M & $A B C A 4$ & $\begin{array}{l}\text { NM_000350.2:c.428del } \\
\text { NM_000350.2:c.(2918 + }\end{array}$ & 5 & Pat & [94] & NM_000350.2:c.5882G > A & 3 & Pat & [40] & \\
\hline S222 & STGD & $36-40$ & M & $A B C A 4$ & $\begin{array}{l}\text { 765_2918 + 775)_(3328 + } \\
\left.618 \_3328+662\right) \text { del }\end{array}$ & 5 & Pat & [18]? & NM_000350.2:c.5603A > T & 3 & Ass & [18] & \\
\hline S223 & ML & $41-45$ & $\mathrm{M}$ & CNGB1 & NM_001297.4:c.1658C > A & 3 & & NA & NM_001297.4:c.2662G > A & 3 & & NA & \\
\hline S224 & STGD & $26-30$ & $\mathrm{M}$ & PRPH2 & NM_000322.4:c.605G > A & 4 & & NA & & & & & \\
\hline S225 & BEST & $41-45$ & $\mathrm{~F}$ & BEST1 & NM_004183.3:c.884_886del & 4 & Pat & [95] & & & & & \\
\hline S227 & STGD & $41-45$ & $\mathrm{M}$ & $A B C A 4$ & NM_000350.2:c.5196 + 2T >C & 5 & Pat & [25] & NM_000350.2:c.5882G > A & 3 & Pat & [40] & Yes (S) \\
\hline S228 & STGD & $11-15$ & $\mathrm{M}$ & $A B C A 4$ & NM_000350.2:c.5882G > A & 3 & Pat & [40] & NM_000350.2:c.6238_6239del & 5 & Pat & [96] & \\
\hline S229 & STGD & $16-20$ & $\mathrm{M}$ & MFSD8 & NM_152778.2:c.670A > T & 3 & & NA & NM_152778.2:c.670A > T & 3 & & NA & \\
\hline $\mathrm{S} 230$ & STGD & $51-55$ & $\mathrm{~F}$ & PRPH2 & NM_000322.4:c.422A > G & 3 & Pat & [97] & & & & & \\
\hline S231 & MD & $51-55$ & $\mathrm{~F}$ & $A B C A 4$ & NM_000350.2:c.2005_2006del & 5 & Pat & [37] & NM_000350.2:c.6148G > C & 4 & Pat & [25] & \\
\hline S232 & STGD & $21-25$ & $\mathrm{~F}$ & $A B C A 4$ & $\begin{array}{l}\text { NM_000350.2:c. }[2588 \mathrm{G}> \\
\text { C;5603A > T] }\end{array}$ & 3 & Pat & [25] & NM_000350.2:c.5762_5763del & 5 & & NA & \\
\hline S233 & STGD & $6-10$ & F & GUCY2D & NM_000180.3:c.2513G > A & 4 & Pat & [98] & & & & & \\
\hline S234 & STGD & $66-70$ & $\mathrm{~F}$ & PRPH2 & NM_000322.4:c.611_626del & 5 & & NA & & & & & \\
\hline S235 & STGD & $51-55$ & M & PRPH2 & $\begin{array}{l}\text { NM_000322.4:c.422A > G } \\
\text { NM_000350.2:c. }(2918+\end{array}$ & 3 & Pat & [97] & & & & & \\
\hline S236 & STGD & $46-50$ & F & $A B C A 4$ & $\begin{array}{l}\text { 765_2918 + 775)_(3328 + } \\
\text { 618_3328 + 662)del }\end{array}$ & 5 & Pat & {$[18] ?$} & NM_000350.2:c.5603A > T & 3 & Ass & [18] & \\
\hline S237 & STGD & $46-50$ & $\mathrm{M}$ & $A B C A 4$ & NM_000350.2:c.4958G > A & 3 & & NA & NM_000350.2:c.5882G > A & 3 & Pat & [40] & \\
\hline S238 & STGD & $16-20$ & $\mathrm{M}$ & $A B C A 4$ & NM_000350.2:c.5714 + 5G > A & 3 & Pat & [42] & NM_000350.2:c.5714 + 5G > A & 3 & Pat & [42] & \\
\hline
\end{tabular}


Table A2. Cont.

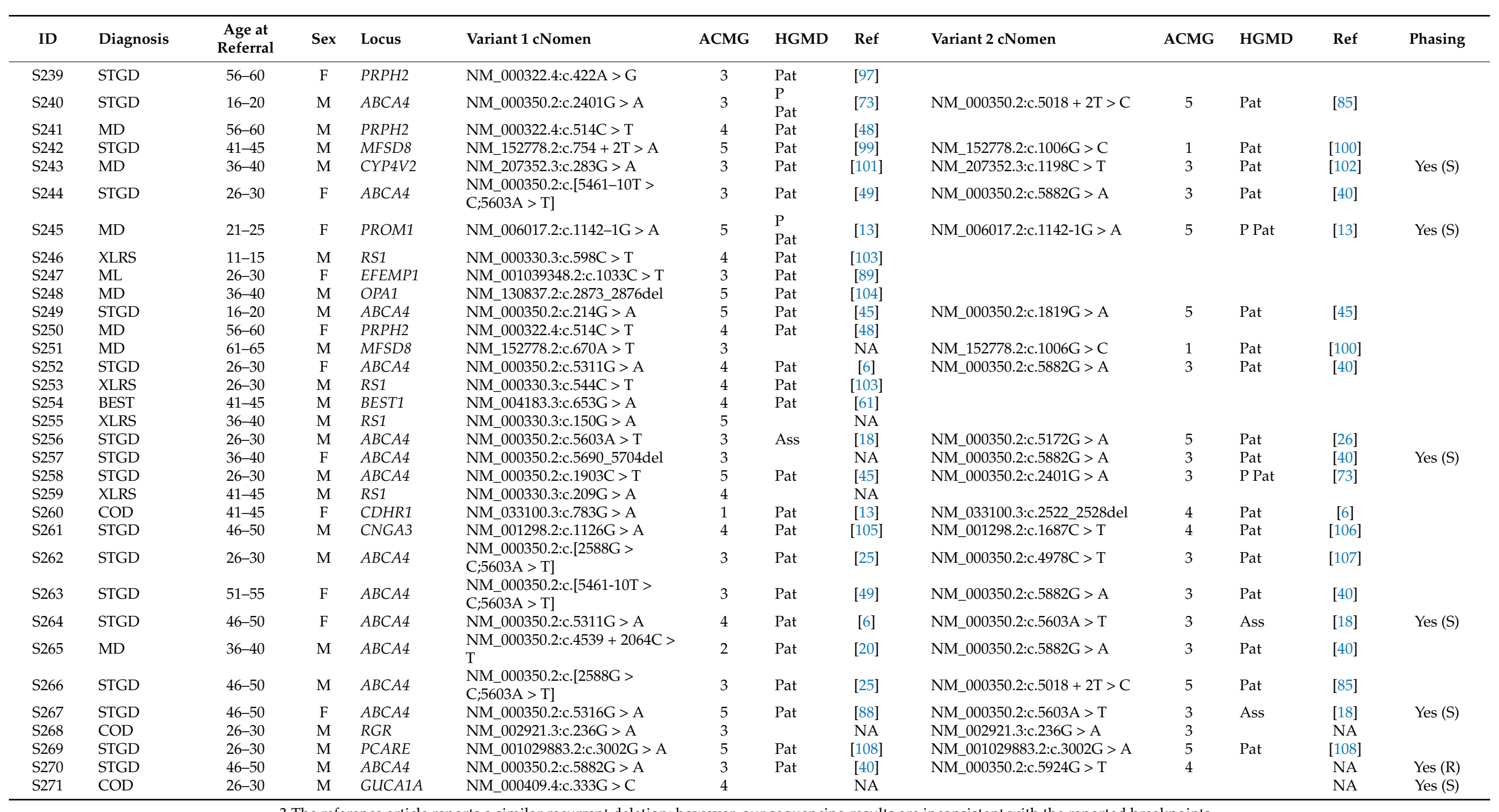

? The reference article reports a similar recurrent deletion; however, our sequencing results are inconsistent with the reported breakpoints. 


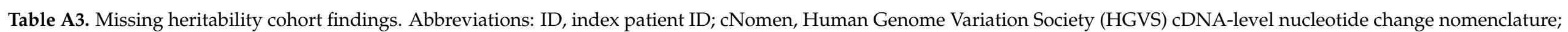

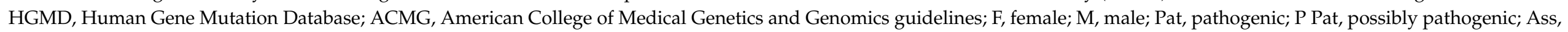
association; Ref, reference; NA, not applicable; S, segregation.

\begin{tabular}{|c|c|c|c|c|c|c|c|c|c|c|c|c|c|}
\hline ID & Diagnosis & $\begin{array}{c}\text { Age at } \\
\text { Referral }\end{array}$ & Sex & Locus & Variant $1 \mathrm{cNomen}$ & ACMG & HGMD & Ref & Variant 2 cNomen & ACMG & HGMD & Ref & Phasing \\
\hline S272 & $\mathrm{RD}$ & $46-50$ & M & $A B C A 4$ & $\begin{array}{l}\text { NM_000350.2:c.[1622T > } \\
\text { C;3113C > T] }\end{array}$ & 4 & Pat & [25] & NM_000350.2:c.5603A > T & 3 & Ass & [18] & \\
\hline S273 & STGD & $6-10$ & M & $A B C A 4$ & NM_000350.2:c.634C > T & 4 & Pat & {$[64]$} & $\begin{array}{l}\text { NM_000350.2:c.5196 + } \\
\text { 1056A > G }\end{array}$ & 3 & P Pat & [64] & Yes (S) \\
\hline S274 & $\mathrm{RD}$ & $66-70$ & $\mathrm{~F}$ & $A B C A 4$ & $\begin{array}{l}\text { NM_000350.2:c. [1622T > } \\
\text { C;3113C > T] }\end{array}$ & 4 & Pat & [25] & NM_000350.2:c.5603A > T & 3 & Ass & [18] & \\
\hline S275 & MD & $31-35$ & M & $A B C A 4$ & NM_000350.2:c.2947A > G & 4 & Pat & {$[71]$} & $\begin{array}{l}\text { NM_000350.2:c. } 4253+43 G \\
>\text { A }\end{array}$ & 2 & P Pat & [22] & \\
\hline S276 & STGD & $41-45$ & M & $A B C A 4$ & NM_000350.2:c.1621_1622del & 4 & & NA & $\begin{array}{l}\text { NM_000350.2:c.5603A > T } \\
\text { NM_000350.2:c.4539 + }\end{array}$ & 3 & Ass & [18] & \\
\hline S277 & STGD & $21-25$ & $\mathrm{~F}$ & $A B C A 4$ & NM_000350.2:c.768G > T & 4 & Pat & [13] & $2064 \mathrm{C}>\mathrm{T}$ & 2 & Pat & {$[20]$} & \\
\hline
\end{tabular}




\section{Appendix B}

Reported here are figures depicting deletions characterization and chromosomal context ( $A B C A 4$ exons $20-22, K C N V 2$ whole gene, and $R S 1$ exon 2, respectively).

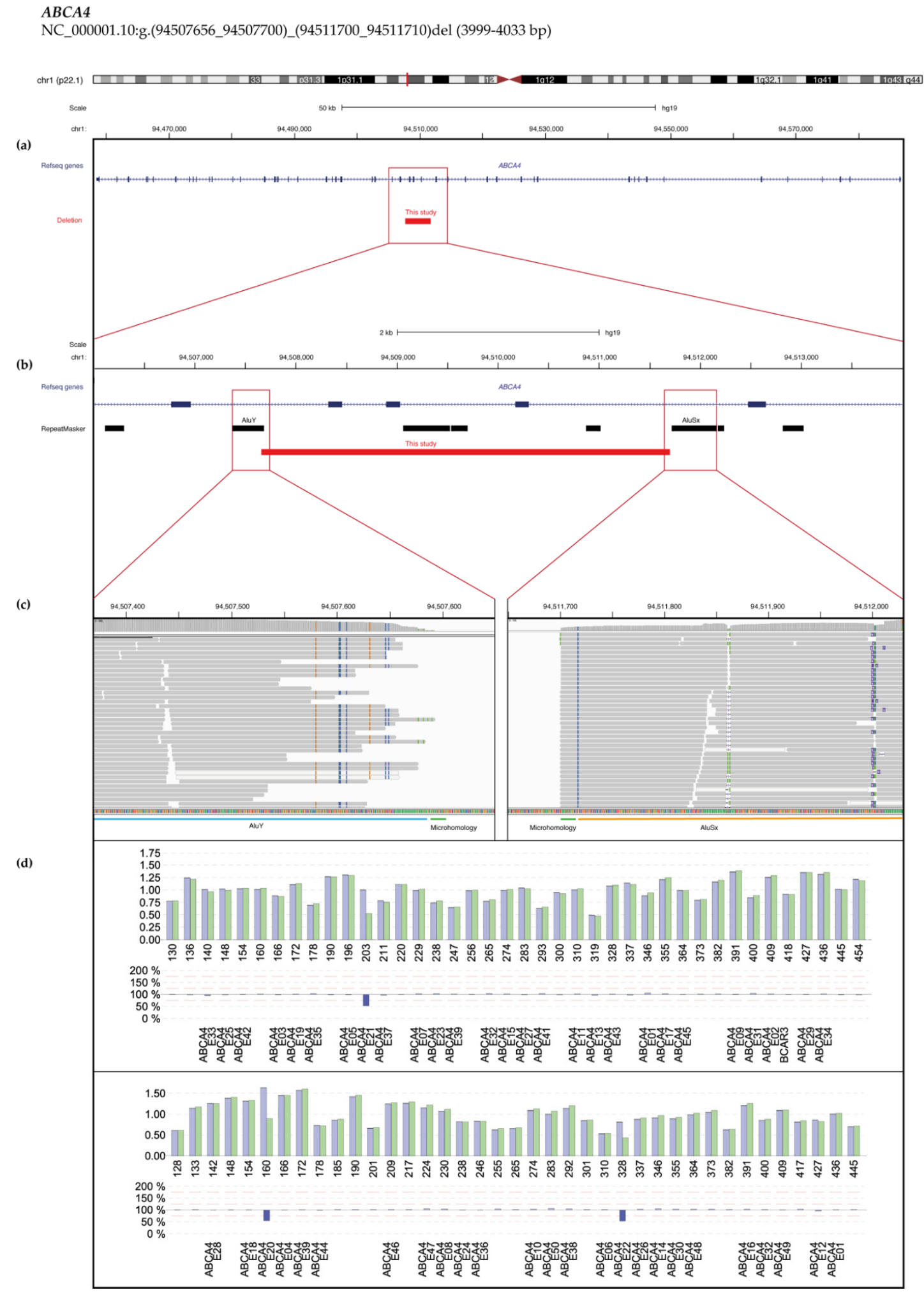

Figure A1. ABCA4 chr1:g.(94507656_94507700)_(94511700_94511710)del (3999-4033 bp), heterozygous. (a) Chromosomal overview and zoom into the $A B C A 4$ locus. The red bar highlights the location and size of the deletion. (b) Magnification of 
the region encompassing exons 19 to 23 of $A B C A 4$. The red bar shows the relative position and size of the deletion. The black bars mark the location of repeat elements from RepeatMasker. Two Alu elements are present in close proximity with both the proximal and distal breakpoints. (c) NGS alignment of the proximal breakpoint region (left, red square in (b)) and of the distal breakpoint region (right, red square in (b)). The alignment shows the location of variants with different colors. The relative location of the Alu elements on the proximal and distal side is highlighted with a blue and an orange line, respectively. The green line shows a $10 \mathrm{bp}-\mathrm{long}$ homologous sequence present on both sides of the deleted region. (d) Screenshot from the MLPA module of Sequence Pilot v5.2 (JSI medical systems, Ettenheim, Germany), depicting MLPA results for kit SALSA Probemix P151 ABCA4 mix-1 (top) and P152 ABCA4 mix-2 (bottom). Blue and green bars represent relative peak areas (RPAs) for controls and proband, respectively. The RPA ratio is illustrated underneath the respective RPA bars, highlighting a heterozygous deletion of exons 21 (mix-1), and 20 and 22 (mix-2).

\section{KCNV2}

NC_000009.11:g.2716981_2787016del (70,036 bp)

NM_133497.3:c.-759_*57289del

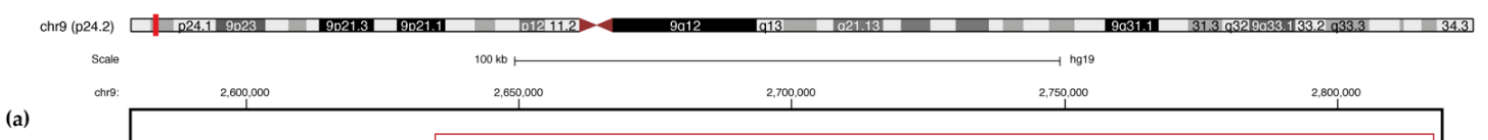

(a)

(b)

(c)
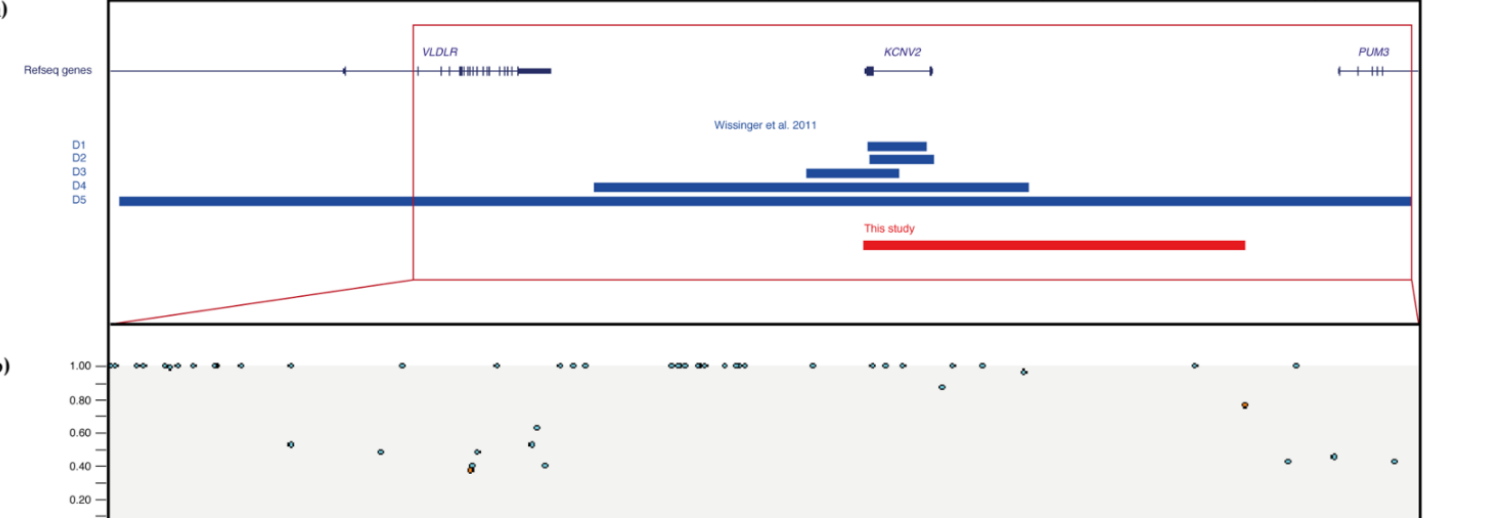

(d)

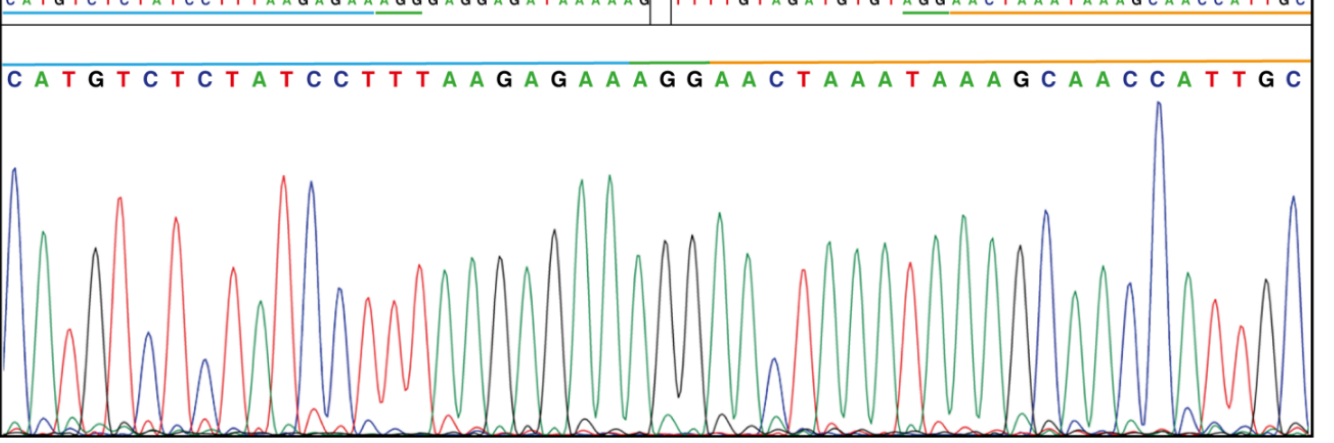

Figure A2. KCNV2 chr9:g.2716981_2787016del (70,036 bp), heterozygous. (a) Chromosomal overview and zoom into the KCNV2 and neighboring genes region. The figure highlights the deletions published previously by Wissinger et al. in 2011 
(blue bars) [109], as well as the position of the one identified in the present study (red bar). (b) CytoSNP-850K BeadChip results for the $K C N V 2$ region (corresponding to the red square in (a)). B-allele frequency plot shown on top and the corresponding log R ratio plot is displayed on the bottom. (c) NGS alignment results for the breakpoint regions. On the left, the 5' side breakpoint alignments are shown. The sequence is illustrated underneath the reads. The blue line underneath the sequence highlights the part of the junction region that originates from the proximal side of the deletion. The green line marks the $3 \mathrm{bp}$-long homologous sequence that is present on both sides of the deleted region. Finally, the orange line shows the part of the sequence coming from the distal side. (d) Electropherogram of the junction fragment for the index patient. The resulting sequence is reported above the peaks. The fragments of the proximal, distal and the shared homologous sequences are highlighted with blue, orange, and green lines, respectively.
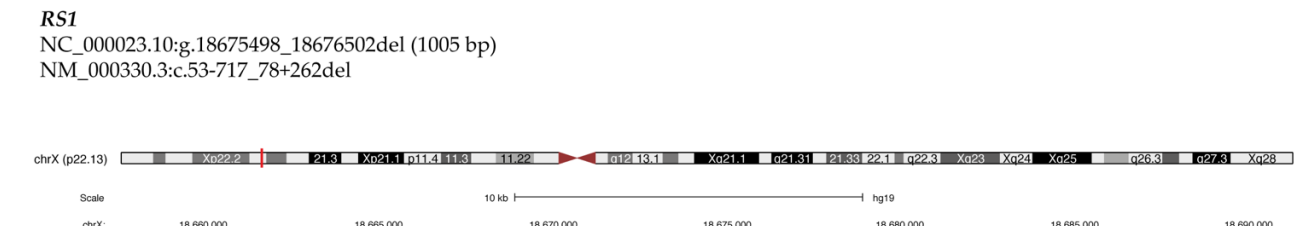

(a)

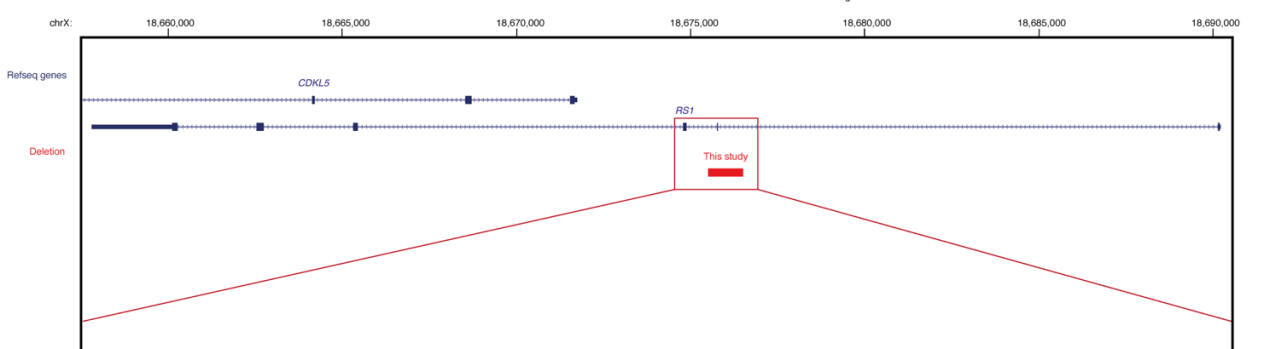

(b)

(c)

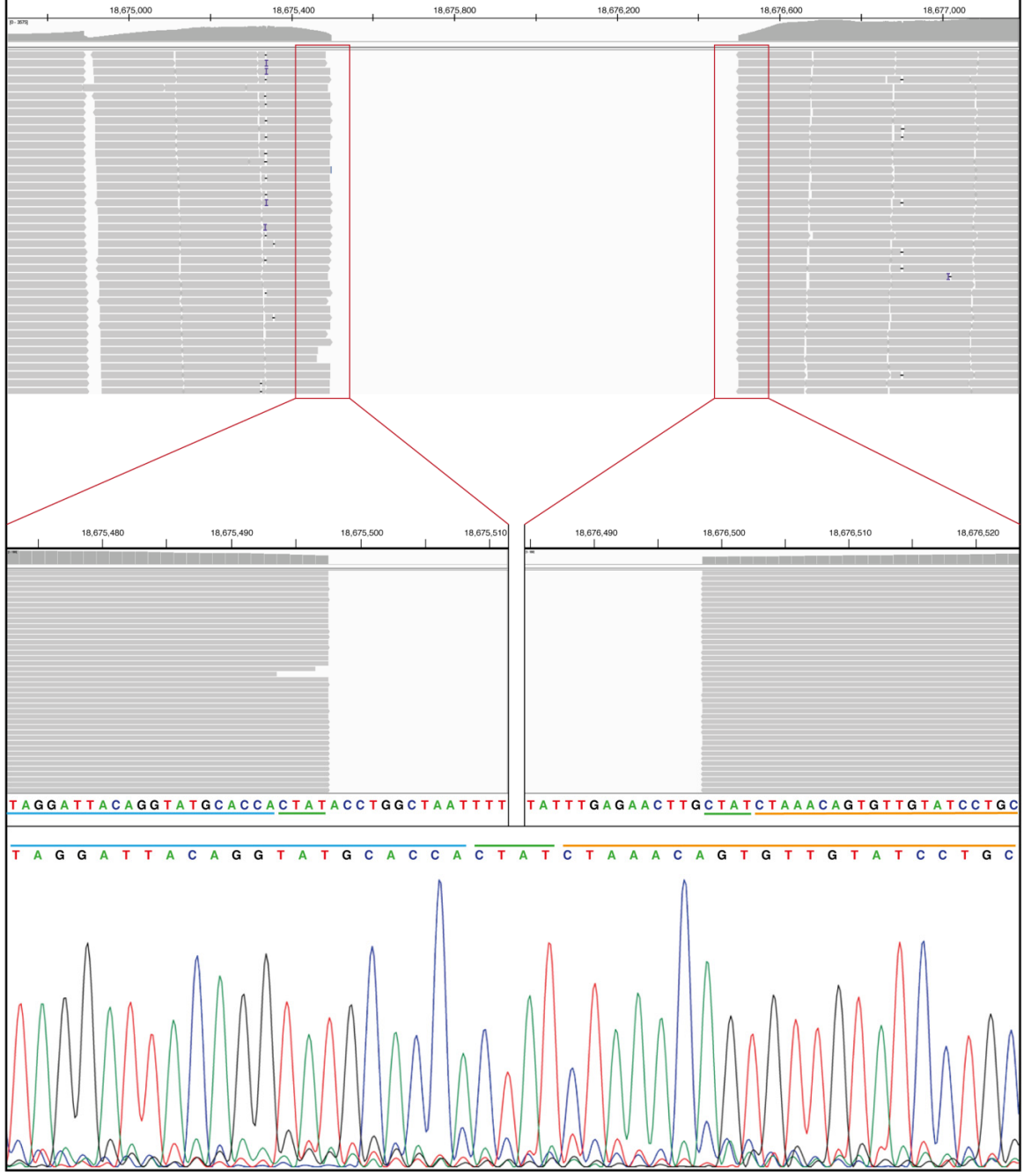

Figure A3. RS1 chrX:g.18675498_18676502del (1005 bp), hemizygous. (a) Chromosomal overview and zoom into the RS1 and neighbouring gene region. The red bar shows the position and size of the deletion. (b) NGS alignment to the red square 
region in (a). (c) Magnification of the $5^{\prime}$ (left) and $3^{\prime}$ (right) breakpoint regions. The corresponding sequence is reported underneath the alignment figure. The blue line under the sequence shows the part of the junction region that originates from the proximal side of the deletion. The green line highlights the $4 \mathrm{bp}$-long homologous sequence that is present on both sides of the deleted region. The orange line marks the part of the sequence coming from the distal side. (d) Electropherogram of the Sanger sequencing results of the junction fragment for the index patient. The blue line above the sequence shows the part of the junction region that originates from the proximal side of the deletion, which can also be seen in the NGS results (c). The green line shows the 4 bp-long homologous sequence that is present on both sides of the deleted region (also marked in (c)). The orange line highlights the part of the sequence coming from the distal side.

\section{References}

1. Berger, W.; Kloeckener-Gruissem, B.; Neidhardt, J. The molecular basis of human retinal and vitreoretinal diseases. Prog. Retin. Eye Res. 2010, 29, 335-375. [CrossRef]

2. Sahel, J.-A.; Marazova, K.; Audo, I. Clinical Characteristics and Current Therapies for Inherited Retinal Degenerations. Cold Spring Harb. Perspect. Med. 2015, 5, a017111. [CrossRef] [PubMed]

3. Roberts, L.; Ratnapriya, R.; Du Plessis, M.; Chaitankar, V.; Ramesar, R.; Swaroop, A. Molecular Diagnosis of Inherited Retinal Diseases in Indigenous African Populations by Whole-Exome Sequencing. Investig. Opthalmol. Vis. Sci. 2016, 57, 6374-6381. [CrossRef] [PubMed]

4. Tiwari, A.; Lemke, J.; Altmueller, J.; Thiele, H.; Glaus, E.; Fleischhauer, J.; Nürnberg, P.; Neidhardt, J.; Berger, W. Identification of Novel and Recurrent Disease-Causing Mutations in Retinal Dystrophies Using Whole Exome Sequencing (WES): Benefits and Limitations. PLoS ONE 2016, 11, e0158692. [CrossRef] [PubMed]

5. Toulis, V.; Cortés-González, V.; De Castro-Miró, M.; Sallum, J.M.F.; Català-Mora, J.; Villanueva-Mendoza, C.; Ciccioli, M.; Gonzàlez-Duarte, R.; Valero, R.; Marfany, G. Increasing the Genetic Diagnosis Yield in Inherited Retinal Dystrophies: Assigning Pathogenicity to Novel Non-canonical Splice Site Variants. Genes 2020, 11, 378. [CrossRef]

6. Weisschuh, N.; Mayer, A.K.; Strom, T.M.; Kohl, S.; Glöckle, N.; Schubach, M.; Andreasson, S.; Bernd, A.; Birch, D.G.; Hamel, C.P.; et al. Mutation Detection in Patients with Retinal Dystrophies Using Targeted Next Generation Sequencing. PLoS ONE 2016, 11, e0145951. [CrossRef]

7. Huang, X.-F.; Huang, F.; Wu, K.-C.; Wu, J.; Chen, J.; Pang, C.-P.; Lu, F.; Qu, J.; Jin, Z.-B. Genotype-phenotype correlation and mutation spectrum in a large cohort of patients with inherited retinal dystrophy revealed by next-generation sequencing. Genet. Med. 2015, 17, 271-278. [CrossRef]

8. Bravo-Gil, N.; Méndez-Vidal, C.; Romero-Pérez, L.; Gonzáles-del Pozo, M.; Rodríguez-de la Rúa, E.; Dopazo, J.; Borrego, S.; Antiñolo, G. Improving the management of Inherited Retinal Dystrophies by targeted sequencing of a population-specific gene panel. Sci. Rep. 2016, 6, 1-10. [CrossRef]

9. Ellingford, J.M.; Barton, S.; Bhaskar, S.; O’Sullivan, J.; Williams, S.G.; Lamb, J.A.; Panda, B.; Sergouniotis, P.I.; Gillespie, R.L.; Daiger, S.P.; et al. Molecular findings from 537 individuals with inherited retinal disease. J. Med Genet. 2016, 53, 761-767. [CrossRef]

10. Kim, M.S.; Joo, K.; Seong, M.-W.; Kim, M.J.; Park, K.H.; Park, S.S.; Woo, S.J. Genetic Mutation Profiles in Korean Patients with Inherited Retinal Diseases. J. Korean Med Sci. 2019, 34, e161. [CrossRef]

11. Beryozkin, A.; Shevah, E.; Kimchi, A.; Mizrahi-Meissonnier, L.; Khateb, S.; Ratnapriya, R.; Lazar, C.H.; Blumenfeld, A.; Ben-Yosef, T.; Hemo, Y.; et al. Whole Exome Sequencing Reveals Mutations in Known Retinal Disease Genes in 33 out of 68 Israeli Families with Inherited Retinopathies. Sci. Rep. 2015, 5, 13187. [CrossRef] [PubMed]

12. Stone, E.M.; Andorf, J.L.; Whitmore, S.S.; DeLuca, A.P.; Giacalone, J.C.; Streb, L.M.; Braun, T.A.; Mullins, R.F.; Scheetz, T.E.; Sheffield, V.C.; et al. Clinically Focused Molecular Investigation of 1000 Consecutive Families with Inherited Retinal Disease. Ophthalmol. 2017, 124, 1314-1331. [CrossRef] [PubMed]

13. Birtel, J.; Eisenberger, T.; Gliem, M.; Müller, P.L.; Herrmann, P.; Betz, C.; Zahnleiter, D.; Neuhaus, C.; Lenzner, S.; Holz, F.G.; et al. Clinical and genetic characteristics of 251 consecutive patients with macular and cone/cone-rod dystrophy. Sci. Rep. $2018,8,4824$. [CrossRef] [PubMed]

14. Perea-Romero, I.; Gordo, G.; Iancu, I.F.; Del Pozo-Valero, M.; Almoguera, B.; Blanco-Kelly, F.; Carreño, E.; Jimenez-Rolando, B.; Lopez-Rodriguez, R.; The ESRETNET Study Group; et al. Genetic landscape of 6089 inherited retinal dystrophies affected cases in Spain and their therapeutic and extended epidemiological implications. Sci. Rep. 2021, 11, 1526. [CrossRef] [PubMed]

15. Maroilley, T.; Tarailo-Graovac, M. Uncovering Missing Heritability in Rare Diseases. Genes 2019, 10, 275. [CrossRef]

16. Braun, T.A.; Mullins, R.F.; Wagner, A.H.; Andorf, J.L.; Johnston, R.M.; Bakall, B.B.; DeLuca, A.P.; Fishman, G.A.; Lam, B.L.; Weleber, R.G.; et al. Non-exomic and synonymous variants in ABCA4 are an important cause of Stargardt disease. Hum. Mol. Genet. 2013, 22, 5136-5145. [CrossRef] [PubMed]

17. Van Cauwenbergh, C.; Van Schil, K.; Cannoodt, R.; Bauwens, M.; Van Laethem, T.; De Jaegere, S.; Steyaert, W.; Sante, T.; Menten, B.; Leroy, B.P.; et al. arrEYE: A customized platform for high-resolution copy number analysis of coding and noncoding regions of known and candidate retinal dystrophy genes and retinal noncoding RNAs. Genet. Med. 2017, 19, 457-466. [CrossRef]

18. Bauwens, M.; Garanto, A.; Sangermano, R.; Naessens, S.; Weisschuh, N.; De Zaeytijd, J.; Khan, M.; Sadler, F.; Balikova, I.; Van Cauwenbergh, C.; et al. ABCA4-associated disease as a model for missing heritability in autosomal recessive disorders: Novel noncoding splice, cis-regulatory, structural, and recurrent hypomorphic variants. Genet. Med. 2019, 21, 1761-1771. [CrossRef] 
19. Ellingford, J.M.; Barton, S.; Bhaskar, S.; Williams, S.G.; Sergouniotis, P.I.; O'Sullivan, J.; Lamb, J.A.; Perveen, R.; Hall, G.; Newman, W.G.; et al. Whole Genome Sequencing Increases Molecular Diagnostic Yield Compared with Current Diagnostic Testing for Inherited Retinal Disease. Ophthalmology 2016, 123, 1143-1150. [CrossRef]

20. Zernant, J.; Xie, Y.A.; Ayuso, C.; Riveiro-Alvarez, R.; Lopez-Martinez, M.-A.; Simonelli, F.; Testa, F.; Gorin, M.B.; Strom, S.P.; Bertelsen, M.; et al. Analysis of the ABCA4 genomic locus in Stargardt disease. Hum. Mol. Genet. 2014, 23, 6797-6806. [CrossRef]

21. Zernant, J.; Schubert, C.; Im, K.M.; Burke, T.; Brown, C.M.; Fishman, G.A.; Tsang, S.H.; Gouras, P.; Dean, M.; Allikmets, R. Analysis of the ABCA4 Gene by Next-Generation Sequencing. Investig. Opthalmology Vis. Sci. 2011, 52, 8479-8487. [CrossRef] [PubMed]

22. Sangermano, R.; Garanto, A.; Khan, M.; Runhart, E.H.; Bauwens, M.; Bax, N.M.; Van den Born, L.I.; Khan, M.I.; Cornelis, S.S.; Verheij, J.B.G.M.; et al. Deep-intronic $A B C A 4$ variants explain missing heritability in Stargardt disease and allow correction of splice defects by antisense oligonucleotides. Genet. Med. 2019, 21, 1751-1760. [CrossRef] [PubMed]

23. Zernant, J.; Lee, W.; Nagasaki, T.; Collison, F.T.; Fishman, G.A.; Bertelsen, M.; Rosenberg, T.; Gouras, P.; Tsang, S.H.; Allikmets, R. Extremely hypomorphic and severe deep intronic variants in the $A B C A 4$ locus result in varying Stargardt disease phenotypes. Cold Spring Harb. Mol. Case Stud. 2018, 4. [CrossRef] [PubMed]

24. Holtan, J.P.; Selmer, K.K.; Heimdal, K.R.; Bragadóttir, R. Inherited retinal disease in Norway - a characterization of current clinical and genetic knowledge. Acta Ophthalmol. 2020, 98, 286-295. [CrossRef]

25. Allikmets, R.; Singh, N.; Sun, H.; Shroyer, N.F.; Hutchinson, A.; Chidambaram, A.; Gerrard, B.; Baird, L.; Stauffer, D.; Peiffer, A.; et al. A photoreceptor cell-specific ATP-binding transporter gene $(A B C R)$ is mutated in recessive Starqardt macular dystrophy. Nat. Genet. 1997, 15, 236-246. [CrossRef]

26. Jiang, F.; Pan, Z.; Xu, K.; Tian, L.; Xie, Y.; Zhang, X.; Chen, J.; Dong, B.; Li, Y. Screening of ABCA4 Gene in a Chinese Cohort with Stargardt Disease or Cone-Rod Dystrophy with a Report on 85 Novel Mutations. Investig. Opthalmol. Vis. Sci. 2016, 57, 145-152. [CrossRef]

27. Carss, K.J.; Arno, G.; Erwood, M.; Stephens, J.; Sanchis-Juan, A.; Hull, S.; Megy, K.; Grozeva, D.; Dewhurst, E.; Malka, S.; et al. Comprehensive rare variant analysis via whole-genome sequencing to determine the molecular pathology of inherited retinal disease. Am. J. Hum. Genet. 2017, 100, 75-90. [CrossRef]

28. Li, J.; Tang, J.; Feng, Y.; Xu, M.; Chen, R.; Zou, X.; Sui, R.; Chang, E.Y.; Lewis, R.A.; Zhang, V.W.; et al. Improved Diagnosis of Inherited Retinal Dystrophies by High-Fidelity PCR of ORF15 followed by Next-Generation Sequencing. J. Mol. Diagn. 2016, 18, 817-824. [CrossRef]

29. Maggi, J.; Roberts, L.; Koller, S.; Rebello, G.; Berger, W.; Ramesar, R. De Novo Assembly-Based Analysis of RPGR Exon ORF15 in an Indigenous African Cohort Overcomes Limitations of a Standard Next-Generation Sequencing (NGS) Data Analysis Pipeline. Genes 2020, 11, 800. [CrossRef]

30. Zhi, D. Sequence correlation between neighboring Alu instances suggests post-retrotransposition sequence exchange due to Alu gene conversion. Gene 2007, 390, 117-121. [CrossRef]

31. Ye, J.; Coulouris, G.; Zaretskaya, I.; Cutcutache, I.; Rozen, S.; Madden, T.L. Primer-BLAST: A tool to design target-specific primers for polymerase chain reaction. BMC Bioinform. 2012, 13, 134. [CrossRef] [PubMed]

32. Li, H.; Durbin, R. Fast and accurate short read alignment with Burrows-Wheeler transform. Bioinformatics 2009, 25, 1754-1760. [CrossRef] [PubMed]

33. Depristo, M.A.; Banks, E.; Poplin, R.; Garimella, K.V.; Maguire, J.R.; Hartl, C.; Philippakis, A.A.; Del Angel, G.; Rivas, M.A.; Hanna, M.; et al. A framework for variation discovery and genotyping using next-generation DNA sequencing data. Nat. Genet. 2011, 43, 491-501. [CrossRef] [PubMed]

34. Povysil, G.; Tzika, A.; Vogt, J.; Haunschmid, V.; Messiaen, L.; Zschocke, J.; Klambauer, G.; Hochreiter, S.; Wimmer, K. panelcn.MOPS: Copy-number detection in targeted NGS panel data for clinical diagnostics. Hum. Mutat. 2017, 38, 889-897. [CrossRef]

35. Bankevich, A.; Nurk, S.; Antipov, D.; Gurevich, A.A.; Dvorkin, M.; Kulikov, A.S.; Lesin, V.M.; Nikolenko, S.I.; Pham, S.; Prjibelski, A.D.; et al. SPAdes: A New Genome Assembly Algorithm and Its Applications to Single-Cell Sequencing. J. Comput. Biol. 2012, 19, 455-477. [CrossRef]

36. Stone, E.M. Leber Congenital Amaurosis-A Model for Efficient Genetic Testing of Heterogeneous Disorders: LXIV Edward Jackson Memorial Lecture. Am. J. Ophthalmol. 2007, 144, 791-811. [CrossRef]

37. Lewis, R.A.; Shroyer, N.F.; Singh, N.; Allikmets, R.; Hutchinson, A.; Li, Y.; Lupski, J.R.; Leppert, M.; Dean, M. Genotype/Phenotype Analysis of a Photoreceptor-Specific ATP-Binding Cassette Transporter Gene, ABCR, in Stargardt Disease. Am. J. Hum. Genet. 1999, 64, 422-434. [CrossRef]

38. Maugeri, A.; Van Driel, M.A.; Van De Pol, D.J.; Klevering, B.J.; Van Haren, F.J.; Tijmes, N.; Bergen, A.A.; Rohrschneider, K.; Blankenagel, A.; Pinckers, A.J.; et al. The 2588G $\rightarrow$ C Mutation in the $A B C R$ Gene Is a Mild Frequent Founder Mutation in the Western European Population and Allows the Classification of ABCR Mutations in Patients with Stargardt Disease. Am. J. Hum. Genet. 1999, 64, 1024-1035. [CrossRef]

39. Paloma, E.; Martínez-Mir, A.; Vilageliu, L.; Gonzàlez-Duarte, R.; Balcells, S. Spectrum of $A B C A 4(A B C R)$ gene mutations in Spanish patients with autosomal recessive macular dystrophies. Hum. Mutat. 2001, 17, 504-510. [CrossRef] 
40. Allikmets, R.; Shroyer, N.F.; Singh, N.; Seddon, J.M.; Lewis, R.A.; Bernstein, P.S.; Peiffer, A.; Zabriskie, N.A.; Li, Y.; Hutchinson, A.; et al. Mutation of the Stargardt Disease Gene $(A B C R)$ in Age-Related Macular Degeneration. Science 1997, 277, $1805-1807$. [CrossRef]

41. Barbazetto, I.A.; Yannuzzi, N.A.; Klais, C.M.; Merriam, J.E.; Zernant, J.; Peiretti, E.; Yannuzzi, L.A.; Allikmets, R. PseudoVitelliform Macular Detachment and Cuticular Drusen: Exclusion of 6 Candidate Genes. Ophthalmic Genet. 2007, 28, 192-197. [CrossRef] [PubMed]

42. Cremers, F.P.M.; Van De Pol, D.J.R.; Van Driel, M.; Den Hollander, A.I.; Van Haren, F.J.J.; Knoers, N.V.A.M.; Tijmes, N.; Bergen, A.A.B.; Rohrschneider, K.; Blankenagel, A.; et al. Autosomal recessive retinitis pigmentosa and cone-rod dystrophy caused by splice site mutations in the Stargardt's disease gene ABCR. Hum. Mol. Genet. 1998, 7, 355-362. [CrossRef] [PubMed]

43. Maugeri, A.; Klevering, B.J.; Rohrschneider, K.; Blankenagel, A.; Brunner, H.G.; Deutman, A.F.; Hoyng, C.B.; Cremers, F.P.M. Mutations in the $A B C A 4(A B C R)$ Gene Are the Major Cause of Autosomal Recessive Cone-Rod Dystrophy. Am. J. Hum. Genet. 2000, 67, 960-966. [CrossRef] [PubMed]

44. Rossi, S.; Testa, F.; Attanasio, M.; Orrico, A.; De Benedictis, A.; Della Corte, M.; Simonelli, F. Subretinal Fibrosis in Stargardt's Disease with Fundus Flavimaculatus and ABCA4 Gene Mutation. Case Rep. Ophthalmol. 2012, 3, 410-417. [CrossRef] [PubMed]

45. Rivera, A.; White, K.; Stöhr, H.; Steiner, K.; Hemmrich, N.; Grimm, T.; Jurklies, B.; Lorenz, B.; Scholl, H.P.N.; Apfelstedt-Sylla, E.; et al. A Comprehensive Survey of Sequence Variation in the $A B C A 4(A B C R)$ Gene in Stargardt Disease and Age-Related Macular Degeneration. Am. J. Hum. Genet. 2000, 67, 800-813. [CrossRef] [PubMed]

46. Krämer, F.; White, K.; Pauleikhoff, D.; Gehrig, A.; Passmore, L.; Rivera, A.; Rudolph, G.; Kellner, U.; Andrassi, M.; Lorenz, B.; et al Mutations in the VMD2 gene are associated with juvenile-onset vitelliform macular dystrophy (Best disease) and adult vitelliform macular dystrophy but not age-related macular degeneration. Eur. J. Hum. Genet. 2000, 8, 286-292. [CrossRef] [PubMed]

47. Vervoort, R.; Lennon, A.; Bird, A.C.; Tulloch, B.; Axton, R.; Miano, M.G.; Meindl, A.; Meitinger, T.; Ciccodicola, A.; Wright, A.F. Mutational hot spot within a new RPGR exon in X-linked retinitis pigmentosa. Nat. Genet. 2000, 25, 462-466. [CrossRef] [PubMed]

48. Wells, J.; Wroblewski, J.; Keen, J.; Inglehearn, C.; Jubb, C.; Eckstein, A.; Jay, M.; Arden, G.B.; Bhattacharya, S.; Fitzke, F.; et al. Mutations in the human retinal degeneration slow (RDS) gene can cause either retinitis pigmentosa or macular dystrophy. Nat. Genet. 1993, 3, 213-218. [CrossRef]

49. Klevering, B.J.; Deutman, A.F.; Maugeri, A.; Cremers, F.P.M.; Hoyng, C.B. The spectrum of retinal phenotypes caused by mutations in the ABCA4 gene. Graefe's Arch. Clin. Exp. Ophthalmol. 2005, 243, 90-100. [CrossRef]

50. Introini, U.; Casalino, G.; Khan, K.N.; Eandi, C.; Alovisi, C.; Michaelides, M.; Bandello, F. Clinical Course of Autosomal Recessive Bestrophinopathy Complicated by Choroidal Neovascularization. Ophthal. Surg. Lasers Imaging Retin. 2018, 49, 888-892. [CrossRef]

51. Thiagalingam, S.; McGee, T.L.; Weleber, R.G.; Sandberg, M.A.; Trzupek, K.M.; Berson, E.L.; Dryja, T.P. Novel Mutations in the KCNV2 Gene in Patients with Cone Dystrophy and a Supernormal Rod Electroretinogram. Ophthalmic Genet. 2007, $28,135-142$. [CrossRef] [PubMed]

52. Schulz, H.L.; Grassmann, F.; Kellner, U.; Spital, G.; Rüther, K.; Jägle, H.; Hufendiek, K.; Rating, P.; Huchzermeyer, C.; Baier, M.J.; et al. Mutation Spectrum of the ABCA4 Gene in 335 Stargardt Disease Patients from a Multicenter German Cohort-Impact of Selected Deep Intronic Variants and Common SNPs. Investig. Opthalmol. Vis. Sci. 2017, 58, 394-403. [CrossRef] [PubMed]

53. Passerini, I.; Sodi, A.; Giambene, B.; Mariottini, A.; Menchini, U.; Torricelli, F. Novel mutations in of the $A B C R$ gene in italian patients with Stargardt disease. Eye 2010, 24, 158-164. [CrossRef] [PubMed]

54. Den Hollander, A.I.; Koenekoop, R.K.; Yzer, S.; Lopez, I.; Arends, M.L.; Voesenek, K.E.J.; Zonneveld, M.N.; Strom, T.M.; Meitinger, T.; Brunner, H.G.; et al. Mutations in the CEP290 (NPHP6) Gene Are a Frequent Cause of Leber Congenital Amaurosis. Am. J. Hum. Genet. 2006, 79, 556-561. [CrossRef] [PubMed]

55. Perrault, I.; Delphin, N.; Hanein, S.; Gerber, S.; Dufier, J.-L.; Roche, O.; Defoort-Dhellemmes, S.; Dollfus, H.; Fazzi, E.; Munnich, A.; et al. Spectrum of NPHP6/CEP290 mutations in Leber congenital amaurosis and delineation of the associated phenotype. Hum. Mutat. 2007, 28, 416. [CrossRef]

56. Jaakson, K.; Zernant, J.; Külm, M.; Hutchinson, A.; Tonisson, N.; Glavač, D.; Ravnik-Glavač, M.; Hawlina, M.; Meltzer, M.; Caruso, R.C.; et al. Genotyping microarray (gene chip) for the ABCR (ABCA4) gene. Hum. Mutat. 2003, 22, 395-403. [CrossRef]

57. Pomares, E.; Riera, M.; Castro-Navarro, J.; Andrés-Gutiérrez, Á.; Gonzàlez-Duarte, R.; Marfany, G. Identification of an Intronic Single-Point Mutation in RP2 as the Cause of Semidominant X-linked Retinitis Pigmentosa. Investig. Opthalmol. Vis. Sci. 2009, 50, 5107-5114. [CrossRef]

58. Sundin, O.H.; Yang, J.-M.; Li, Y.; Zhu, D.; Hurd, J.N.; Mitchell, T.N.; Silva, E.D.; Maumenee, I.H. Genetic basis of total colourblindness among the Pingelapese islanders. Nat. Genet. 2000, 25, 289-293. [CrossRef]

59. White, K.; Marquardt, A.; Weber, B.H.F. VMD2 mutations in vitelliform macular dystrophy (Best disease) and other maculopathies. Hum. Mutat. 2000, 15, 301-308. [CrossRef]

60. Sodi, A.; Bini, A.; Passerini, I.; Forconi, S.; Menchini, U.; Torricelli, F. Different Patterns of Fundus Autofluorescence Related to ABCA4 Gene Mutations in Stargardt Disease. Ophthal. Surg. Lasers Imaging 2010, 41, 48-53. [CrossRef]

61. Lotery, A.; Munier, F.L.; A Fishman, G.; Weleber, R.G.; Jacobson, S.G.; Affatigato, L.M.; E Nichols, B.; Schorderet, D.F.; Sheffield, V.C.; Stone, E.M. Allelic variation in the VMD2 gene in best disease and age-related macular degeneration. Investig. Ophthalmol. Vis. Sci. 2000, 41, 1291-1296. 
62. Boon, C.J.F.; Van Den Born, L.I.; Visser, L.; Keunen, J.E.; Bergen, A.A.B.; Booij, J.C.; Riemslag, F.C.; Florijn, R.J.; Van Schooneveld, M.J. Autosomal Recessive Bestrophinopathy: Differential Diagnosis and Treatment Options. Ophthalmology 2013, 120, 809-820. [CrossRef] [PubMed]

63. Tiwari, A.; Bahr, A.; Bähr, L.; Fleischhauer, J.; Zinkernagel, M.S.; Winkler, N.; Barthelmes, D.; Berger, L.; Gerth-Kahlert, C.; Neidhardt, J.; et al. Next generation sequencing based identification of disease-associated mutations in Swiss patients with retinal dystrophies. Sci. Rep. 2016, 6, 28755. [CrossRef] [PubMed]

64. Gerber, S.; Rozet, J.-M.; Van De Pol, T.J.R.; Hoyng, C.B.; Munnich, A.; Blankenagel, A.; Kaplan, J.; Cremers, F.P.M. Complete Exon-Intron Structure of the Retina-Specific ATP Binding Transporter Gene $(A B C R)$ Allows the Identification of Novel Mutations Underlying Stargardt Disease. Genomics 1998, 48, 139-142. [CrossRef]

65. Kuniyoshi, K.; Ikeo, K.; Sakuramoto, H.; Furuno, M.; Yoshitake, K.; Hatsukawa, Y.; Nakao, A.; Tsunoda, K.; Kusaka, S.; Shimomura, Y.; et al. Novel nonsense and splice site mutations in CRB1 gene in two Japanese patients with early-onset retinal dystrophy. Doc. Ophthalmol. 2015, 130, 49-55. [CrossRef]

66. Maugeri, A.; Meire, F.; Hoyng, C.B.; Vink, C.; Van Regemorter, N.; Karan, G.; Yang, Z.; Cremers, F.P.M.; Zhang, K. A Novel Mutation in the ELOVL4 Gene Causes Autosomal Dominant Stargardt-like Macular Dystrophy. Investig. Opthalmol. Vis. Sci. 2004, 45, 4263-4267. [CrossRef]

67. Corton, M.; Tatu, S.D.; Avila-Fernandez, A.; Vallespín, E.; Tapias, I.; Cantalapiedra, D.; Blanco-Kelly, F.; Riveiro-Alvarez, R.; Bernal, S.; García-Sandoval, B.; et al. High frequency of CRB1 mutations as cause of Early-Onset Retinal Dystrophies in the Spanish population. Orphanet J. Rare Dis. 2013, 8, 20. [CrossRef]

68. Den Hollander, A.I.; Ten Brink, J.B.; De Kok, Y.J.M.; Van Soest, S.; Van Den Born, L.I.; Van Driel, M.A.; Van De Pol, D.J.; Payne, A.M.; Bhattacharya, S.S.; Kellner, U.; et al. Mutations in a human homologue of Drosophila crumbs cause retinitis pigmentosa (RP12). Nat. Genet. 1999, 23, 217-221. [CrossRef]

69. Payne, A.; Vithana, E.; Khaliq, S.; Hameed, A.; Deller, J.; Abu-Safieh, L.; Kermani, S.; Leroy, B.P.; Mehdi, S.Q.; Moore, A.T.; et al. RP1 protein truncating mutations predominate at the RP1 adRP locus. Investig. Ophthalmol. Vis. Sci. 2000, 41, 4069-4073.

70. Yokoyama, A.; Maruiwa, F.; Hayakawa, M.; Kanai, A.; Vervoort, R.; Wright, A.F.; Yamada, K.; Niikawa, N.; Naōi, N. Three novel mutations of the RPGR gene exon ORF15 in three Japanese families with X-linked retinitis pigmentosa. Am. J. Med Genet. 2001, 104, 232-238. [CrossRef]

71. Ernest, P.J.G.; Boon, C.J.F.; Klevering, B.J.; Hoefsloot, L.H.; Hoyng, C.B. Outcome of $A B C A 4$ microarray screening in routine clinical practice. Mol. Vis. 2009, 15, 2841-2847. [PubMed]

72. Simonelli, F.; Testa, F.; De Crecchio, G.; Rinaldi, E.; Hutchinson, A.; Atkinson, A.; Dean, M.; D’Urso, M.; Allikmets, R. New ABCR mutations and clinical phenotype in Italian patients with Stargardt disease. Investig. Ophthalmol. Vis. Sci. 2000, 41, 892-897.

73. Downs, K.; Zacks, D.N.; Caruso, R.; Karoukis, A.J.; Branham, K.; Yashar, B.M.; Haimann, M.H.; Trzupek, K.; Meltzer, M.; Blain, D.; et al. Molecular Testing for Hereditary Retinal Disease as Part of Clinical Care. Arch. Ophthalmol. 2007, 125, 252-258. [CrossRef] [PubMed]

74. Stenirri, S.; Alaimo, G.; Manitto, M.P.; Brancato, R.; Ferrari, M.; Cremonesi, L. Are microarrays useful in the screening of $A B C A 4$ mutations in Italian patients affected by macular degenerations? Clin. Chem. Lab. Med. 2008, 46, 1250-1255. [CrossRef]

75. Abed, E.; Placidi, G.; Campagna, F.; Federici, M.; Minnella, A.; Guerri, G.; Bertelli, M.; Piccardi, M.; Galli-Resta, L.; Falsini, B. Early impairment of the full-field photopic negative response in patients with Stargardt disease and pathogenic variants of the ABCA4 gene. Clin. Exp. Ophthalmol. 2018, 46, 519-530. [CrossRef]

76. Meunier, I.; Sénéchal, A.; Dhaenens, C.-M.; Arndt, C.; Puech, B.; Defoort-Dhellemmes, S.; Manes, G.; Chazalette, D.; Mazoir, E.; Bocquet, B.; et al. Systematic Screening of BEST1 and PRPH2 in Juvenile and Adult Vitelliform Macular Dystrophies: A Rationale for Molecular Analysis. Ophthalmology 2011, 118, 1130-1136. [CrossRef]

77. Johnson, A.A.; Lee, Y.-S.; Chadburn, A.J.; Tammaro, P.; Manson, F.D.; Marmorstein, L.Y.; Marmorstein, A.D. Disease-causing mutations associated with four bestrophinopathies exhibit disparate effects on the localization, but not the oligomerization, of Bestrophin-1. Exp. Eye Res. 2014, 121, 74-85. [CrossRef]

78. Özgül, R.K.; Durukan, H.; Turan, A.; Öner, C.; Öğ̈̈s, A.; Farber, D.B. Molecular analysis of the ABCA4 gene in Turkish patients with Stargardt disease and retinitis pigmentosa. Hum. Mutat. 2004, 23, 523. [CrossRef]

79. Testa, F.; Rossi, S.; Sodi, A.; Passerini, I.; Di Iorio, V.; Della Corte, M.; Banfi, S.; Surace, E.M.; Menchini, U.; Auricchio, A.; et al. Correlation between Photoreceptor Layer Integrity and Visual Function in Patients with Stargardt Disease: Implications for Gene Therapy. Investig. Opthalmol. Vis. Sci. 2012, 53, 4409-4415. [CrossRef]

80. Webster, A.R.; Héon, E.; Lotery, A.; Vandenburgh, K.; Casavant, T.L.; Oh, K.T.; Beck, G.; Fishman, G.A.; Lam, B.L.; Levin, A.; et al. An analysis of allelic variation in the ABCA4 gene. Investig. Ophthalmol. Vis. Sci. 2001, 42, 1179-1189.

81. Sauer, C.G.; Gehrig, A.; Warneke-Wittstock, R.; Marquardt, A.; Ewing, C.C.; Gibson, A.; Lorenz, B.; Jurklies, B.; Weber, B.H. Positional cloning of the gene associated with X-linked juvenile retinoschisis. Nat. Genet. 1997, 17, 164-170. [CrossRef] [PubMed]

82. Rozet, J.-M.; Gerber, S.; Souied, E.; Perrault, I.; Châtelin, S.; Ghazi, I.; Leowski, C.; Dufier, J.-L.; Munnich, A.; Kaplan, J. Spectrum of $A B C R$ gene mutations in autosomal recessive macular dystrophies. Eur. J. Hum. Genet. 1998, 6, 291-295. [CrossRef] [PubMed]

83. Stenirri, S.; Fermo, I.; Battistella, S.; Galbiati, S.; Soriani, N.; Paroni, R.; Manitto, M.P.; Martina, E.; Brancato, R.; Allikmets, R.; et al. Denaturing HPLC Profiling of the ABCA4 Gene for Reliable Detection of Allelic Variations. Clin. Chem. 2004, 50, 1336-1343. [CrossRef] [PubMed] 
84. Gerth-Kahlert, C.; Koller, S.; Hanson, J.V.M.; Baehr, L.; Tiwari, A.; Kivrak-Pfiffner, F.; Bahr, A.; Berger, W. Genotype-Phenotype Analysis of a Novel Recessive and a Recurrent Dominant SNRNP200 Variant Causing Retinitis Pigmentosa. Investig. Opthalmol. Vis. Sci. 2019, 60, 2822-2835. [CrossRef]

85. Cideciyan, A.V.; Swider, M.; Aleman, T.S.; Tsybovsky, Y.; Schwartz, S.B.; Windsor, E.A.; Roman, A.J.; Sumaroka, A.; Steinberg, J.D.; Jacobson, S.G.; et al. ABCA4 disease progression and a proposed strategy for gene therapy. Hum. Mol. Genet. 2009, 18, 931-941. [CrossRef] [PubMed]

86. Souied, E.H.; Ducroq, D.; Rozet, J.M.; Gerber, S.; Perrault, I.; Sterkers, M.; Benhamou, N.; Munnich, A.; Coscas, G.; Soubrane, G.; et al. A novel $A B C R$ nonsense mutation responsible for late-onset fundus flavimaculatus. Investig. Ophthalmol. Vis. Sci. 1999, $40,2740-2744$.

87. Kohl, S.; Baumann, B.; Broghammer, M.; Jägle, H.; Sieving, P.; Kellner, U.; Spegal, R.; Anastasi, M.; Zrenner, E.; Sharpe, L.T.; et al. Mutations in the CNGB3 gene encoding the $\beta$-subunit of the cone photoreceptor cGMP-gated channel are responsible for achromatopsia (ACHM3) linked to chromosome 8q21. Hum. Mol. Genet. 2000, 9, 2107-2116. [CrossRef]

88. Briggs, C.E.; Rucinski, D.; Rosenfeld, P.J.; Hirose, T.; Berson, E.L.; Dryja, T.P. Mutations in $A B C R(A B C A 4)$ in patients with Stargardt macular degeneration or cone-rod degeneration. Investig. Ophthalmol. Vis. Sci. 2001, 42, 2229-2236.

89. Stone, E.M.; Lotery, A.J.; Munier, F.L.; Héon, E.; Piguet, B.; Guymer, R.H.; Vandenburgh, K.; Cousin, P.; Nishimura, D.; Swiderski, R.E.; et al. A single EFEMP1 mutation associated with both Malattia Leventinese and Doyne honeycomb retinal dystrophy. Nat. Genet. 1999, 22, 199-202. [CrossRef]

90. Arai, Y.; Maeda, A.; Hirami, Y.; Ishigami, C.; Kosugi, S.; Mandai, M.; Kurimoto, Y.; Takahashi, M. Retinitis Pigmentosa with EYS Mutations Is the Most Prevalent Inherited Retinal Dystrophy in Japanese Populations. J. Ophthalmol. 2015, 2015, 1-10. [CrossRef]

91. Hejtmancik, J.F.; Jiao, X.; Li, A.; Sergeev, Y.V.; Ding, X.; Sharma, A.K.; Chan, C.-C.; Medina, I.; Edwards, A.O. Mutations in KCNJ13 Cause Autosomal-Dominant Snowflake Vitreoretinal Degeneration. Am. J. Hum. Genet. 2008, 82, 174-180. [CrossRef] [PubMed]

92. Barboni, P.; Savini, G.; Cascavilla, M.L.; Caporali, L.; Milesi, J.; Borrelli, E.; La Morgia, C.; Valentino, M.L.; Triolo, G.; Lembo, A.; et al. Early Macular Retinal Ganglion Cell Loss in Dominant Optic Atrophy: Genotype-Phenotype Correlation. Am. J. Ophthalmol. 2014, 158, 628-636. [CrossRef] [PubMed]

93. Smailhodzic, D.; Fleckenstein, M.; Theelen, T.; Boon, C.J.F.; Van Huet, R.A.C.; Van De Ven, J.P.H.; Den Hollander, A.I.; SchmitzValckenberg, S.; Hoyng, C.B.; Weber, B.H.F.; et al. Central Areolar Choroidal Dystrophy (CACD) and Age-Related Macular Degeneration (AMD): Differentiating Characteristics in Multimodal Imaging. Investig. Opthalmol. Vis. Sci. 2011, 52, 8908-8918. [CrossRef] [PubMed]

94. Hu, F.-Y.; Li, J.-K.; Gao, F.-J.; Qi, Y.-H.; Xu, P.; Zhang, Y.-J.; Wang, D.-D.; Wang, L.-S.; Li, W.; Wang, M.; et al. ABCA4 Gene Screening in a Chinese Cohort with Stargardt Disease: Identification of 37 Novel Variants. Front. Genet. 2019, 10, 773. [CrossRef] [PubMed]

95. Marquardt, A.; Stöhr, H.; Passmore, L.A.; Krämer, F.; Rivera, A.; Weber, B.H.F. Mutations in a novel gene, VMD2, encoding a protein of unknown properties cause juvenile-onset vitelliform macular dystrophy (Best's disease). Hum. Mol. Genet. 1998, 7, 1517-1525. [CrossRef]

96. Yatsenko, A.N.; Shroyer, N.F.; Lewis, R.A.; Lupski, J.R. Late-onset Stargardt disease is associated with missense mutations that map outside known functional regions of $A B C R$ (ABCA4). Hum. Genet. 2001, 108, 346-355. [CrossRef]

97. Sohocki, M.M.; Daiger, S.P.; Bowne, S.J.; Rodriquez, J.A.; Northrup, H.; Heckenlively, J.R.; Birch, D.G.; Mintz-Hittner, H.; Ruiz, R.S.; Lewis, R.A.; et al. Prevalence of mutations causing retinitis pigmentosa and other inherited retinopathies. Hum. Mutat. 2001, 17, 42-51. [CrossRef]

98. Payne, A.M.; Morris, A.G.; Downes, S.M.; Johnson, S.; Bird, A.C.; Moore, A.T.; Bhattacharya, S.S.; Hunt, D.M. Clustering and frequency of mutations in the retinal guanylate cyclase (GUCY2D) gene in patients with dominant cone-rod dystrophies. J. Med Genet. 2001, 38, 611-614. [CrossRef]

99. Siintola, E.; Topcu, M.; Aula, N.; Lohi, H.; Minassian, B.A.; Paterson, A.D.; Liu, X.-Q.; Wilson, C.; Lahtinen, U.; Anttonen, A.-K.; et al. The Novel Neuronal Ceroid Lipofuscinosis Gene MFSD8 Encodes a Putative Lysosomal Transporter. Am. J. Hum. Genet. 2007, 81, 136-146. [CrossRef]

100. Roosing, S.; Van Den Born, L.I.; Sangermano, R.; Banfi, S.; Koenekoop, R.K.; Zonneveld-Vrieling, M.N.; Klaver, C.C.W.; Van Lith-Verhoeven, J.J.; Cremers, F.P.M.; Den Hollander, A.I.; et al. Mutations in MFSD8, Encoding a Lysosomal Membrane Protein, Are Associated with Nonsyndromic Autosomal Recessive Macular Dystrophy. Ophthalmology 2015, 122, 170-179. [CrossRef]

101. Shan, M.; Dong, B.; Zhao, X.; Wang, J.; Li, G.; Yang, Y.; Li, Y. Novel mutations in the CYP4V2 gene associated with Bietti crystalline corneoretinal dystrophy. Mol. Vis. 2005, 11, 738-743. [PubMed]

102. Lai, T.Y.Y.; Ng, T.K.; Tam, P.O.S.; Yam, G.H.F.; Ngai, J.W.S.; Chan, W.-M.; Liu, D.T.L.; Lam, D.S.C.; Pang, C.P. Genotype-Phenotype Analysis of Bietti's Crystalline Dystrophy in Patients with CYP4V2 Mutations. Investig. Opthalmol. Vis. Sci. 2007, 48, 5212-5220. [CrossRef] [PubMed]

103. Den Dunnen, J.T.; Kraayenbrink, T.; Van Schooneveld, M.; Van de Vosse, E.; Ten Brink, J.B.; Schuurman, E.; Tijmes, N.; Van Ommen, G.; Bergen, A.A.; Andolfi, G.; et al. Functional Implications of the Spectrum of Mutations Found in 234 Cases With X-linked Juvenile Retinoschisis (XLRS). Hum. Mol. Genet. 1998, 7, 1185-1192. [CrossRef]

104. Delettre, C.; Lenaers, G.; Griffoin, J.-M.; Gigarel, N.; Lorenzo, C.; Belenguer, P.; Pelloquin, L.; Grosgeorge, J.; Turc-Carel, C.; Perret, E.; et al. Nuclear gene OPA1, encoding a mitochondrial dynamin-related protein, is mutated in dominant optic atrophy. Nat. Genet. 2000, 26, 207-210. [CrossRef] 
105. Koeppen, K.; Reuter, P.; Ladewig, T.; Kohl, S.; Baumann, B.; Jacobson, S.G.; Plomp, A.S.; Hamel, C.P.; Janecke, A.R.; Wissinger, B. Dissecting the pathogenic mechanisms of mutations in the pore region of the human cone photoreceptor cyclic nucleotide-gated channel. Hum. Mutat. 2010, 31, 830-839. [CrossRef]

106. Koeppen, K.; Reuter, P.; Kohl, S.; Baumann, B.; Ladewig, T.; Wissinger, B. Functional analysis of human CNGA3 mutations associated with colour blindness suggests impaired surface expression of channel mutants A3R427C and A3R563C. Eur. J. Neurosci. 2008, 27, 2391-2401. [CrossRef]

107. Cideciyan, A.V.; Swider, M.; Aleman, T.S.; Feuer, W.J.; Schwartz, S.B.; Russell, R.C.; Steinberg, J.D.; Stone, E.M.; Jacobson, S.G. Macular Function in Macular Degenerations: Repeatability of Microperimetry as a Potential Outcome Measure for ABCA4Associated Retinopathy Trials. Investig. Opthalmol. Vis. Sci. 2012, 53, 841-852. [CrossRef]

108. Audo, I.; Lancelot, M.-E.; Mohand-Saï, S.; Antonio, A.; Germain, A.; Sahel, J.-A.; Bhattacharya, S.S.; Zeitz, C. Novel C2orf71 mutations account for $\sim 1 \%$ of cases in a large French arRP cohort. Hum. Mutat. 2011, 32, E2091-E2103. [CrossRef]

109. Wissinger, B.; Schaich, S.; Baumann, B.; Bonin, M.; Jägle, H.; Friedburg, C.; Varsányi, B.; Hoyng, C.B.; Dollfus, H.; Heckenlively, J.R.; et al. Large deletions of the KCNV2 gene are common in patients with cone dystrophy with supernormal rod response. Hum. Mutat. 2011, 32, 1398-1406. [CrossRef] 